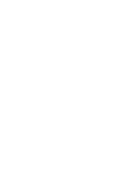
$\underset{\text { ANNUAL Further }}{\text { REVES }}$

Click here for quick links to Annual Reviews content online, including:

- Other articles in this volume

- Top cited articles

- Top downloaded articles

- Our comprehensive search

Annu. Rev. Genet. 2013. 47:377-404

The Annual Review of Genetics is online at genet.annualreviews.org

This article's doi:

10.1146/annurev-genet-111212-133343

Copyright (c) 2013 by Annual Reviews. All rights reserved

\section{The Digestive Tract of Drosopbila melanogaster}

\author{
Bruno Lemaitre ${ }^{1}$ and Irene Miguel-Aliaga ${ }^{2}$
}

${ }^{1}$ Global Health Institute, School of Life Sciences, École Polytechnique Fédérale Lausanne (EPFL), CH-1015 Lausanne, Switzerland; email: bruno.lemaitre@epfl.ch

${ }^{2}$ MRC Clinical Sciences Center, Imperial College London, London W12 0NN, United Kingdom; email: i.miguel-aliaga@imperial.ac.uk

\section{Keywords}

gut, Drosophila, digestion, absorption, enteroendocrine cells, enteric nervous system, intestine, immunity

\begin{abstract}
The digestive tract plays a central role in the digestion and absorption of nutrients. Far from being a passive tube, it provides the first line of defense against pathogens and maintains energy homeostasis by exchanging neuronal and endocrine signals with other organs. Historically neglected, the gut of the fruit fly Drosophila melanogaster has recently come to the forefront of Drosophila research. Areas as diverse as stem cell biology, neurobiology, metabolism, and immunity are benefitting from the ability to study the genetics of development, growth regulation, and physiology in the same organ. In this review, we summarize our knowledge of the Drosophila digestive tract, with an emphasis on the adult midgut and its functional underpinnings.
\end{abstract}




\section{INTRODUCTION}

Peritrophic matrix (PM): a noncellular matrix composed of chitin and glycoprotein that lines the invertebrate midgut and separates the food bolus from the epithelium

Proventriculus: the foregut portion of the cardia. Proventriculus is often used to describe the entire cardia
The gut is one of the largest organs in the body cavity. Aside from its central role in digesting and absorbing nutrients, the inner lining of the digestive tract must also serve as the first line of defense against a wide variety of pathogens. The gut is also a major source of neuronal and endocrine signals able to modulate nutrient storage or food intake by regulating the activity of other organs, such as the pancreas and the brain in mammals. Hence, far from being a passive tube exclusively concerned with digestion, the gut is emerging as a major regulator of multiple biological processes. As a result, what had historically been a relatively obscure organ is now coming to the forefront of research in areas as diverse as stem cell biology, neurobiology, metabolism, and immunity.

The gut has also been a relatively understudied organ in Drosophila melanogaster, given that, since the advent of the genetic revolution, this model system has played such a central role in the investigation of developmental processes. Consequently, physiological studies have typically been relegated to less genetically amenable insects, possibly because of their larger size (50). The potential to combine genetic and functional approaches in Drosophila has only been realized in recent years, and concurrent with this, there has been a surge of interest in the fly gut and its functions. In this review, we summarize our knowledge - at times fragmented or sketchy —of the Drosophila digestive tract, with an emphasis on the adult midgut and its functional underpinnings.

\section{STRUCTURE OF THE DROSOPHILA DIGESTIVE TRACT}

The emergence of the gastrointestinal tract within the body cavity was a major innovation in animal evolution, allowing the transition from an intracellular to an extracellular mode of digestion (169). In bilaterians, the digestive tract further evolved into a succession of histologically distinct regions tailored to specific digestive needs. Hence, the dietary requirements of Drosophila (consisting primarily of fermenting fruit) resulted in an alimentary canal similar to that of other dipterans feeding on decaying matter, such as the housefly Musca domestica (49, 52, 102, 126, 182). Two prominent features can be discerned from an examination of the anatomical and cellular architecture of the Drosophila gut: its compartmentalization and plasticity, both of which have been best characterized in the adult midgut.

\section{Compartmentalization of the Digestive Tract}

As in other insects, the Drosophila gut consists of a simple epithelium, surrounded by visceral muscles, nerves, and tracheae. The nature and arrangement of these different cell types differ widely depending on their position along the length of the gut. Different developmental origins account for some of these differences, as in the digestive epithelium, which is subdivided into foregut, midgut, and hindgut (43, 66, 67, 94, 152, 162) (Figure 1 $\boldsymbol{a}, \boldsymbol{b}$ ). The foregut and hindgut epithelium are of ectodermal origin and are lined on the apical side by an impermeable cuticle. In contrast, the midgut epithelium is of endodermal origin and is protected on the luminal side by the peritrophic matrix (PM) (Figure 1d ). The adult midgut is further subdivided into six major anatomical regions (R0 to R5) with distinct metabolic and digestive functions (23). These six regions are separated by narrow epithelial boundaries. Some of them are surrounded by anatomically distinct sets of muscles, suggesting a sphincter-like role in regulating the movement of food. Some of these boundaries are also inflection points where the midgut folds stereotypically inside the body cavity. Detailed genetic and histological analyses have revealed further regionalization of these midgut regions (see Figure $\mathbf{1} \boldsymbol{a}, \boldsymbol{b}$ for more details) $(23,107 a)$. Such regionalization appears to be a general property of the Drosophila digestive tract given that it has also been observed in the proventriculus and larval midgut and hindgut $(94,120,121)$. 
a

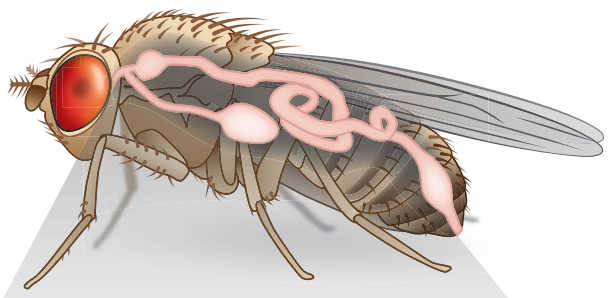

b

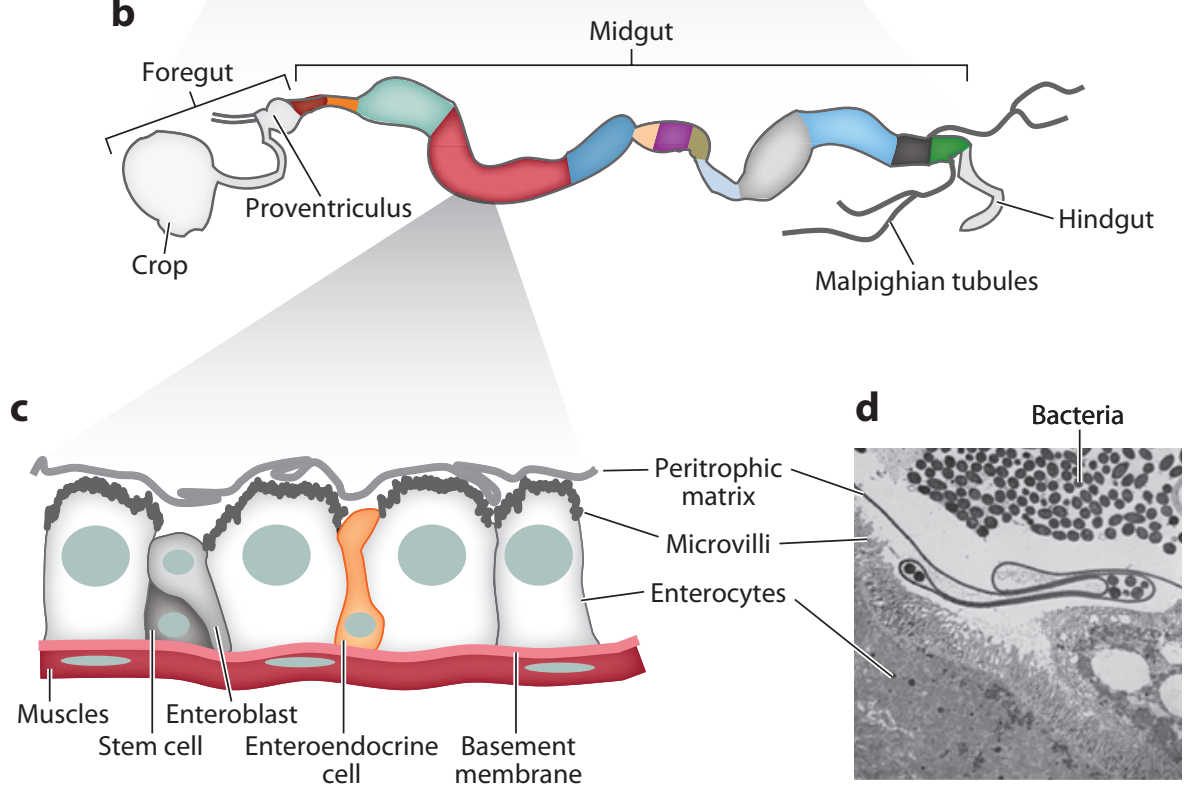

Figure 1

Schematic organization of the Drosophila digestive tract. (a) A 3D reconstruction of the digestive tract within the body cavity (23). (b) The digestive tract is divided into three discrete domains of different developmental origin: foregut, midgut, and hindgut. Each of these domains is further subdivided into genetically distinct compartments (illustrated by different colors in the case of the midgut). (c) The midgut is composed of an epithelium surrounded by two layers of visceral muscles. The midgut epithelium consists of enterocytes, enteroendocrine cells (EEC), and progenitor cells. (d) Electron microscopy sections of a third-instar larval gut following infection with Erwinia carotovora 15 (2). The peritrophic matrix establishes a physical barrier that prevents contact between bacteria and the epithelial cell.

Compartmentalization is achieved and maintained through the combinatorial action of pan-gut and region-specific transcription factors. For instance, in the middle midgut, the so-called copper-cell region relies on the activity of two region-specific homeobox proteins, Labial and Ptx1, and a pan-midgut transcription factor, GATAe $(23,56,83,135)$. Gene expression boundaries are not always sharp, espe- cially in the vicinity of boundaries where graded gene expression appears to be widespread and relies in part on the Wnt pathway (23). This suggests that these boundaries are gut tissueorganizing centers where Wingless may act as a morphogen, akin to its function in patterning embryos or imaginal discs.

Finally, it is noteworthy that larvae and adults differ in the anatomical and genetic 
Crop: an enlarged diverticulum of the foregut used to store food before it enters the midgut organization of their digestive tract, plausibly as a result of their different dietary habits. Whereas larvae feed continuously to sustain their growth and are able to ingest solid food thanks to their mouth hooks, adult flies feed less frequently, ingesting liquid via their proboscis. This intermittent ingestion of liquid may account for the presence of the crop, a storage organ found only in adults (170). Features specific to larval guts include the presence of four gastric ceca in the anterior midgut, which are major sites of digestion and absorption, at least in other insects (126). Thus, the adaptive changes of these gut regions during the fly's life cycle further illustrate the gut's structural complexity and highlight another notable feature of this organ: its plasticity.

\section{The Drosophila Gut: A Plastic Organ}

As in other holometabolous insects, the adult Drosophila gut is generated de novo during metamorphosis. In fact, three distinct gastrointestinal tissues supersede one another during development: the larval gut (arising from the embryonic gut), the transient pupal gut, and the adult gut (see References 109, 124, 176, 178 for details). After metamorphosis, both the larval and pupal midgut degenerate to form meconium, which is expelled soon after eclosion.

The adult midgut epithelium contains two main types of differentiated cells: enterocytes and enteroendocrine cells (EECs) (Figure 1c). Enterocytes (also called columnar cells in other insects) are large polyploid cells that secrete digestive enzymes and absorb nutrients. Although enterocytes differ markedly in morphology along the gut, most of them are positive for the MyoIA-Gal4 driver (inserted in the Myosin 31DF gene). Interspersed among the enterocyte monolayer are small nucleated prospero-positive EECs (113, 134, 175). Whereas the larval gut is postmitotic and undergoes massive growth by increases in cell size coupled with polyploidization, the adult gut is capable of regeneration. As in other insects (49, $102,126)$, the adult midgut is constantly replaced by new cells derived from small regen- erative cells [named intestinal stem cells (ISCs) in Drosophila] scattered across the basal surface of the gut epithelium $(113,134)$. Midgut ISCs undergo either asymmetric or symmetric division(s). In asymmetric divisions, one daughter cell maintains ISC characteristics and remains mitotic, whereas the other daughter cell (also known as an enteroblast) exits the cell cycle and differentiates into either an absorptive enterocyte or an EEC, an outcome determined by Notch signaling activity (133). Differentiating enterocytes endoreplicate their genome two to three times to increase their size and develop a brush border on their apical side.

All midgut ISCs and enteroblasts (referred to together as progenitor cells) express the marker gene escargot. Nevertheless, distinct populations of self-renewing stem cells have been identified along the digestive tract. For instance, the copper-cell region is renewed by a specific population of ISCs that, unlike other midgut ISCs, are largely quiescent (172). Similarly, another subpopulation of self-renewing cells is found in the foregut-midgut junction and may contribute to the maintenance of the proventriculus (167). In the hindgut, stem cells are restricted to a narrow segment known as the hindgut proliferation zone located at the midgut-hindgut boundary (177). The existence of different stem cell populations may contribute to the establishment of different regional identities. Alternatively, or in parallel, surrounding tissues, such as visceral muscles and tracheae, could provide region-specific niche signals to differentiating ISC lineages to impart regional identity to their progeny (23, 107a).

The midgut epithelium is renewed within one to two weeks under steady-state conditions $(113,134)$. Stem cell activity is influenced by the metabolic state of the host and by environmental factors (reviewed in 89, 176). In the fed state, localized insulin signaling increases ISC activity and drives tissue growth (131). Increased stem cell activity is also observed upon intestinal damage by corrosive agents or pathogenic bacteria. This allows the rapid regeneration of the compromised gut and maintains barrier 
integrity $(4,22,90)$. The activity of a number of pathways, namely the JAK-STAT, epidermal growth factor (EGF) receptor, decapentaplegic (DPP), and Wingless/Myc pathways, stimulates the proliferation and differentiation of progenitor cells into enterocytes (40, 72, 90, 105; see References 89, 176 for reviews). Upon damage, these pathways are activated by the release of EGFs, Wingless, and JAK-STAT ligands (Upd3, Upd2) from damaged enterocytes or progenitors, thus establishing a compensatory homeostatic loop. Interestingly, the visceral muscles that surround the epithelium contribute to epithelium renewal by producing the EGF ligand Vein $(89,90,176)$. An outstanding question in the regeneration field is to identify the cells and signals that initiate the complex homeostatic loop that leads to epithelial regeneration. One possible trigger may be the release of Upd2 and Upd3 by enterocytes, either in response to stress or following rupture of the adjacent epithelium and consequent activation of the Hippo pathway (reviewed in 89, 176).

\section{Senescence of the Adult Gut}

The plasticity of the gut is further highlighted by the changes it undergoes during adult life. Ultrastructural observations in the 1970s and 1980s revealed that aging alters the adult midgut and is associated with increased lipid deposits, autophagic vacuoles, and the appearance of ballooned mitochondria $(6,65)$. More recently, other studies have shown that old Drosophila guts display defective compartmentalization (23) and become leaky (148) and dysplastic, as defined by a higher rate of stem cell proliferation and accumulation of undifferentiated progenitors $(12,35)$. This dysplasia is perhaps not surprising given that, as one of the most highly mitotic adult organs, the gut must strike a balance with regard to stem cell activity, allowing regeneration while minimizing the risk of hyperplasia. Interestingly, a link between life span and stem cell activity was recently reported by Biteau et al. (13), who observed that maximal life span is achieved when intesti- nal proliferation is reduced rather than totally inhibited.

Mechanistically, little is known about the molecular effectors of these aging hallmarks, but there are some intriguing correlations. Indeed, gut senescence is associated with the chronic activation of the stress-responsive JNK pathway and with elevated reactive oxygen species (ROS) levels in the gut (12). A link between ROS, mitochondria, gut senescence, and aging is further supported by the observation that life span can be extended upon overexpression of dPGC-1, a regulator of mitochondrial biogenesis in the gut (147). Interestingly, aged flies also have higher bacterial loads in their gut $(21,146)$, and axenic flies display attenuated and delayed intestinal dysplasia, suggesting that gut-associated bacteria contribute to the disorganization of the gut in aged flies, possibly by modulating epithelium turnover (21). Barrier dysfunction in old guts also correlates with shorter life span and higher expression of immune genes by the fat body (148). An emerging theme from these somewhat disparate observations is that the intestine may be an important modulator of life span at the organismal level.

\section{THE DROSOPHILA GUT: A SELECTIVE BARRIER}

The digestive tract forms a selective barrier that allows absorption of nutrients, ions, and water but limits contact with potentially damaging agents, such as toxins and pathogens. This selectivity is enabled by specialized physical barriers and a potent mucosal immune system.

\section{Peritrophic Matrix and Mucus}

Most metazoans, including vertebrates, isolate their intestinal epithelium from the external environment with one or more carbohydrate-rich barriers (e.g., mucus). In insects, the foregut and hindgut are lined by a relatively impermeable cuticle, whereas the midgut is protected by the peritrophic matrix (PM) (Figure 1 $\boldsymbol{d}$ ). Almost nothing is known about the composition, organization, and role of these barriers in Drosophila. 
Endoperitrophic space: part of the lumen located inside the peritrophic matrix

Ectoperitrophic space: part of the lumen located between the peritrophic matrix and the midgut epithelium

Antimicrobial peptides: small cationic peptides that are able to kill bacteria

Peptidoglycan recognition protein (PGRP): a family of proteins that can bind to peptidoglycan, a specific component of bacterial cell walls
The PM is believed to be an organized lattice composed of chitin fibrils held together by secreted chitin-binding proteins, notably peritrophins $(79,101)$. Electron microscopy indicates that the adult PM is secreted as four layers in the proventriculus, which are probably compressed by muscular contraction of the proventricular walls to coalesce into two layers as they enter the midgut $(94,152)$. Peristalsis may propel the PM as far as the hindgut. Consistent with this, transcripts encoding PM components (e.g., peritrophin) are strongly enriched in the proventriculus (23). The observation that peritrophin genes are also expressed in a more distal part of the midgut suggests that this barrier is remodeled along the gut (23). To date, no fly devoid of PM has been generated, suggesting that this matrix is essential for viability. Nevertheless, a mutation in the drosocrystallin gene, a structural element of the PM, results in reduced PM thickness and higher permeability and is associated with higher susceptibility to ingested entomopathogenic bacteria or pore-forming toxins (96). A protective role for the PM against abrasive food particles and pathogens as well as in sequestering ingested toxins has already been described (79, 101). Studies in other insects further suggest that the PM plays an essential role in digestion by partitioning the lumen into two distinct compartments, the endoperitrophic and the ectoperitrophic spaces, which contain different digestive enzymes (183).

In addition to the PM, the existence of a mucous layer is suggested by the fact that the apical surface of midgut epithelial cells is positive for periodic acid-Schiff (23): a staining method used to detect mucosubstances. Although more than 30 Drosophila genes have been annotated as mucin-like proteins (174), the functional relevance of these genes or, more generally, of mucus in the gut has not been investigated.

\section{Drosophila Gut Immunity}

The Drosophila gut is proving to be a good model to study interactions between stress, repair, and immune responses/tolerance to com- mensal bacteria (see References 21a, 42, 61 for reviews).

Ingestion of gram-negative bacteria triggers the expression of several antimicrobial peptide genes in specific domains along the digestive tract (187). Although most of these genes are under the control of the Imd pathway, some antifungal Drosomycin-like peptide genes are also induced in the anterior midgut by the JAK-STAT pathway, probably in response to epithelial damage $(22,136,198)$. In the gut, the Imd pathway is activated by two pattern-recognition receptors of the peptidoglycan recognition protein (PGRP) family: the transmembrane PGRP-LC receptor (which plays a predominant role in the foregut and the hindgut) and the intracellular PGRPLE sensor (the role of which is restricted to the midgut) $(15,127)$. Both receptors are activated upon recognition of diaminopimelic acid (DAP)-type peptidoglycan, a cell wall component of gram-negative bacteria and certain gram-positive bacterium (e.g., Bacillus). Several negative regulators downregulate the Imd pathway to prevent its activation by indigenous bacteria or ingested bacteria and to tailor its activity to the severity of infection. Negative regulators include secreted amidases that scavenge peptidoglycans (the bacterial ligand of the Imd pathway) and Pirk, which disrupts signaling between the PGRP-LC receptor and its downstream adaptor, Imd $(104,139,198)$. Although the Imd pathway is activated all along the gut, transcription factors, such as the homeobox Caudal, restrict the expression of a subset of Imd target genes (157). This additional level of regulation explains why genes encoding antimicrobial peptides are expressed in specific domains (157).

A complementary line of defense involves the production of ROS by the NADPH oxidase Duox (74). Duox is thought to be present on the apical surface of the gut epithelium and is enriched in the foregut and hindgut. Duox activity is stimulated upon recognition by an as yet uncharacterized G-coupled receptor of uracile, a microbially derived ligand that is proposed to be released by pathogenic bacteria (100). Duox 
is also regulated at the transcriptional level by the p38 MAPK pathway and the ATF2 transcription factor (73). Excessive production of ROS is circumvented by an inducible catalase (75) and by negative regulators of Duox activity (73).

In addition to these signaling pathways, acidity, peristalsis, and the PM (96) may all contribute to bacterial clearance. Indeed, most ingested bacteria do not survive passage through the acidic zone. The crop also produces many detoxifying enzymes (e.g., glutathion Stransferase), which may detoxify the bolus prior to its entry into the midgut. To date, there is no evidence of any blood cells intimately associated with the gut, although a population of plasmatocytes with macrophage capacity resides within the folds of the larval proventriculus $(31,152,199)$. Gut infection can lead to intestinal damage, which can be caused by bacterial toxins or by an overaggressive, and thus deleterious, immune response. Stress response programs and increased epithelial renewal can then be deployed to repair the intestinal epithelium and maintain the integrity of the gut barrier $(21,32,33,90)$.

\section{DIGESTIVE ENZYMES AND DIGESTION}

In the intestine, the complex mix of dietary components ingested by flies is broken down by digestive enzymes before it is absorbed by the intestinal epithelium. Digestion is also influenced by the physicochemical conditions of the gut (notably $\mathrm{pH}$ ) and the enzymatic activity of microbes (49). Although digestion in Diptera may also occur in the crop or extra-orally, both digestion and absorption are predominantly accomplished in the midgut (102).

\section{Digestive Enzymes}

The Drosophila genome encodes a vast array of putative digestive enzymes involved in the processing of carbohydrates, proteins, and lipidsas many as 349 based on bioinformatic predictions (Figure 2a). Endopeptidases and exopep- tidases [involved in the initial and final steps of protein digestion, respectively] are particularly abundant $(28,155,180)$. There are also 52 and 29 proteins with predicted carbohydrase and lipase activity, respectively $(84,85)$ (Figure $2 a$ ). This diverse enzymatic repertoire may be optimized to deal with the nature and complexity of the diet of Drosophila, which is rich in decaying fruits. In this regard, it is interesting to note the presence of 15 genes encoding lysozymes, which hydrolyze peptidoglycan, a major component of bacterial cell walls. Given that no immune role has been ascribed to Drosophila lysozymes, it is possible that they are involved in digestion (97). Thus, their high gene copy number strongly suggests that bacteria make up a significant proportion of the Drosophila diet in the wild. In addition, the Drosophila genome also encodes chitinases and glucanases that may participate in the digestion of yeasts that are also found in rotting fruits.

Most digestive gene families are organized in tight genomic clusters, with each member of the cluster being differentially expressed along the digestive tract (23) (Figure 2b). This applies to Jonah proteases, trypsins, $\alpha$-esterases, mannosidases, and lipases (23). These clusters may have arisen by gene duplication followed by divergence in order to optimize enzymatic activities in each portion of the digestive tract-an evolutionary process suggested by the extensive studies of the Drosophila $\alpha$-amylase gene family (41, 201).

Expression analyses of several digestive enzyme genes suggest sequential processing of nutrients along the intestine. For instance, amylases (catalyzing the breakdown of starches) are found in midgut regions R2 and R4, whereas enzymes involved in the processing of simple carbohydrates are mostly found in R4, R5, and the hindgut $(1,23)$. However, it remains to be established whether this restricted expression is maintained, given that digestive enzymes may diffuse to a considerable distance in the gut lumen. The peritrophic membrane may be an important tissue to consider in this regard. In Rhynchosciara americana larvae, initial digestion is carried out by polymer hydrolases within the
Plasmatocytes: Drosophila hemocytes with macrophage activity 
a

Carbohydrase
Amylase
Mannosidase
Glucosidase
Trehalase
Beta-galactosidase
Lysozyme
Chitinase
Amidase PGRP
Proteinasae
Aminopeptidase
Carboxypeptidase
Cysteine-type endopeptidase
Aspartic-type endopeptidase
Serine-type endopeptidase
Metalloendopeptidase
Peptidyl-dipeptidase
Lipase and esterase
Lipase
Carboxylesterase
Phospholipase
Sphingomyelin
phosphodiesterase
Phosphodiesterase

b
10
2

15
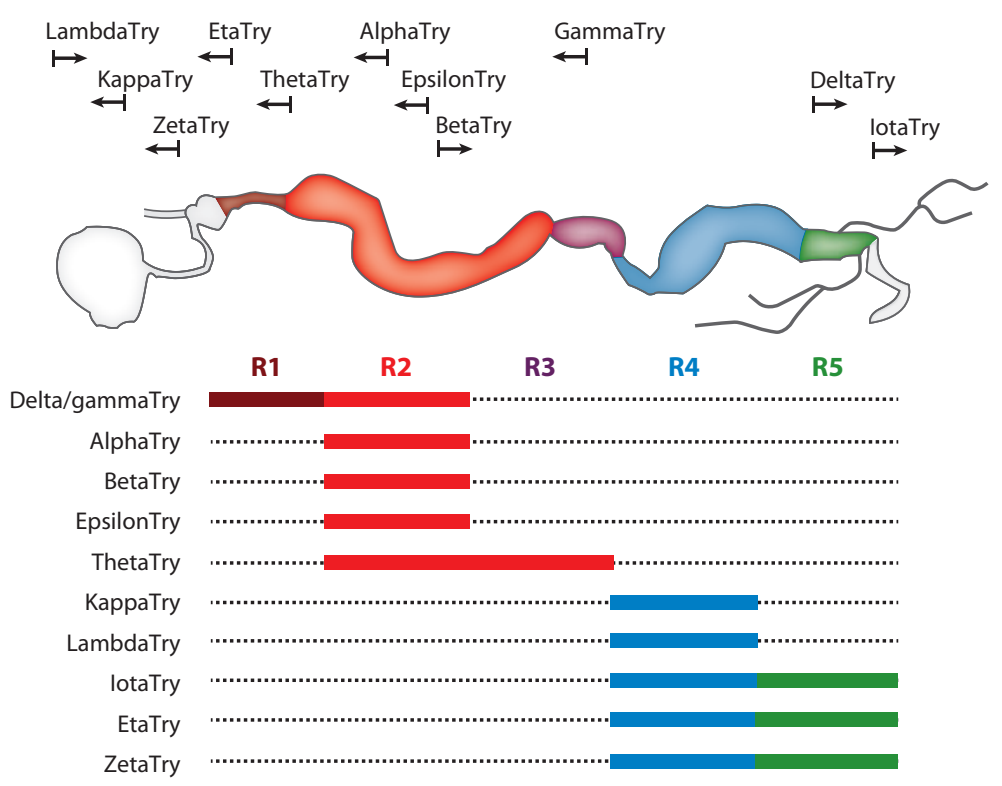

C Polysaccharide (e.g., starch)

Amylases
$2 \mathrm{R}$

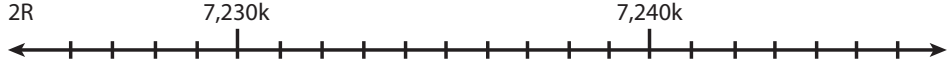

GammaTry

Monosaccharide

(e.g., glucose/fructose)
Glucosidase

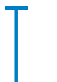

Glucose repression

Figure 2

Digestive enzymes. (a) List of putative Drosophila digestive enzyme genes. Genes were identified based on the following criteria: ability to encode an enzyme (gene ontology) with a signal peptide and significant gene expression enrichment in one of the following organs: salivary gland, crop, midgut, and hindgut. See complete table and details at http://lemaitrelab.epfl.ch/resources. (b) (Top) Eleven trypsin genes are clustered together on chromosome II. (Bottom) The expression of each gene of this cluster is enriched in different regions of the midgut (see color code corresponding to R1-5) (23). (c) Digestion of carbohydrates by the sequential action of amylase and glucosidases. The presence of glucose inhibits the expression of amylase. Abbreviation: PGRP, peptidoglycan recognition protein.

Paracrine: a form of cell signaling in which the target cell is near the signal-releasing cell

Prandial: relating to food ingestion peritrophic membrane, giving rise to products of lower molecular weight, which then diffuse out of the peritrophic membrane. The second phase of digestion occurs in the ectoperitrophic fluid, followed by a final digestion step primarily confined to the microvilli of the midgut, where enzymes are trapped in the glycocalyx $(49,184)$. Although the existence of such a degree of spatial organization with regard to digestion has not been investigated in Drosophila, vesicles containing the lipase Magro are se- creted into the larval gut lumen in the same region of the proventriculus as the PM (164), raising the possibility that vesicular trafficking in this region may function to load the PM with digestive enzymes.

\section{Regulation of Digestive Enzymes}

Digestive enzymes are subject to complex regulation by neural, systemic, paracrine, and prandial mechanisms $(102,103,194)$. Modulation 
of enzyme expression by nutrient quantity or quality has been observed in several arthropods $(36,194)$. One of the rare characterized examples of digestive enzyme regulation in Drosophila concerns carbohydrate digestion and involves repression of enzymes important in the initial phase of digestion by digestive end products. Indeed, sucrose and its products, glucose and fructose, have been shown to repress amylase gene expression-an effect described as glucose repression $(1,10,185)$ (Figure 2c). This reduction in digestive capacity may well be a metabolic adaptation to limit dietary sugar absorption during periods of nutritional abundance, given that Drosophila is poorly adapted to nutritional excess (122). Mechanistically, reduced amylase activity results from downregulation of gene transcription. Although the mechanism of transcriptional repression remains to be established, this finding suggests that digestive genes receive inputs from regional transcription factors that define their site of expression and from metabolic transcription factors that adjust their expression levels to match organismal requirements. Two other factors known to influence digestion are starvation and bacterial infection, which typically downregulate the transcription of digestive enzymes, perhaps to spare resources (22, 203). The existence of additional levels of regulation at the posttranscriptional level (e.g., protein release) has not been investigated.

\section{Functional Studies}

With rare exceptions, the precise roles of digestive enzymes have not been established. Using an inversion mutant in which both amylase $p$ and $d$ are affected (amy $\left.{ }^{\text {null }}\right)$ (82), it was shown that amylase-deficient flies perish on a starchonly diet. However, lethality can be rescued by dietary supplementation with simple sugars, which are the end products of amylase digestion. Interestingly, a different study reported that amylase-deficient flies were able to survive on a starch-only medium only when they were housed with wild-type flies (76). This finding led the authors to posit the existence of extra- oral digestion, with wild-type flies regurgitating amylases onto the medium, which would predigest carbohydrates on the food surface. Another functional study concerned the lipase Magro, expressed in the proventriculus under the control of the transcription factor DHR96 $(86,164)$. Downregulation of either magro or DHR96 by RNAi rendered larvae unable to break down dietary triglyceride in their gut lumen, leading to reduced triglyceride stores (164). This phenotype was rescued by feeding larvae pancreatin, a mixture of pancreatic enzymes that includes triglyceride lipase.

\section{The Drosophila Midgut pH}

Nutrient breakdown and enzymatic activity are strongly affected by the physicochemical properties of the lumen. Whereas mammalian digestion takes place in acidic conditions, insect digestion occurs at neutral or basic pHs. In Drosophila adults, the initially neutral $\mathrm{pH}$ of the anterior midgut is followed by an acidic zone $(\mathrm{pH}<4)$ that corresponds to the copper-cell region. The posterior midgut is mildly alkaline $(\mathrm{pH}=7-9)$, whereas the hindgut is slightly acidic $(\mathrm{pH}=5)$, although its $\mathrm{pH}$ can fluctuate depending on the fly's diet $(37,53,162)$. Akin to the mammalian stomach, the midgut acidic zone denatures proteins and provides an optimal $\mathrm{pH}$ for the activity of some peptidases. It probably also kills microorganisms that are ingested with the food and facilitates the absorption of lipids and metals. The role of the copper cells [a pool of highly differentiated cells in R3 $(53,162)]$ in acid production has been established in larvae that lack the labial or alphaspectrin genes, which affect the differentiation or shape of these copper cells, respectively (55). Acid secretion is thought to involve the polarized activity of an apical multi-subunit $\mathrm{V}$ ATPase (vacuolar-type $\mathrm{H}^{+}$-ATPase) pump that exports $\mathrm{H}^{+}$in the lumen in exchange for energy in the form of ATP $(51,161)$. Several VATPases enriched in the copper-cell region of the adult gut (such as vha100-4) are good candidates to mediate the acidification of this midgut region (23).
Vacuolar-type $\mathrm{H}^{+}$-ATPase (V-ATPase): a multi-subunit transporter that couples the energy of ATP hydrolysis to proton transport across the intracellular or plasma membranes of eukaryotic cells 
Hemolymph: insect blood

Transcellular transport: transport of solutes by a cell through a cell

\section{Drosophila Gut-Associated Microbes and Their Role in Digestion}

Drosophila feed on decaying fruit, and their digestive tract is therefore constantly exposed to dietary microbes, which may themselves contribute to digestion. The Drosophila gut lumen is an environment with relatively low bacterial diversity and numbers (1-30 species, $10^{3}-10^{5}$ CFU/fly) (30, 156, 191, 192; reviewed in 17, $48,59)$. The most prevalent bacterial species are members of the genera Lactobacillus and Acetobacter. The existence of a stable population of dividing bacteria residing in the gut has not yet been formally demonstrated, as bacteria found in the Drosophila gut are also found in the substratum, suggesting constant contamination. Experiments with germ-free flies (raised in the absence of both internal and external bacteria) have shown that gut-associated bacteria can be beneficial to Drosophila by promoting growth in poor dietary conditions $(151,163$, 171). How bacteria contribute to growth has yet to be established, but they are not merely a food source given that growth promotion was only observed in the presence of live bacteria. Live bacteria may predigest food, change its nutritional content, and/or improve digestion inside the gut. In addition to their contribution to Drosophila growth, gut bacteria also stimulate intestinal epithelial turnover and influence the basal level of antimicrobial peptide gene expression in the gut $(21,156,163)$.

Less studied than gut-associated bacteria, yeasts play an important role in Drosophila nutrition by providing many essential nutrients, such as amino acids, sterols, B vitamins, and fatty acids: compounds not generally present in decaying plant material (see 17 and references therein).

\section{ABSORPTION AND STORAGE}

Absorption refers to the uptake of luminal contents across the intestine to the hemolymph (49). Most absorption is via transcellular transport, requiring specific transporters at both the apical and basal sides of enterocytes, and is likely to be regulated. Hence, far from being a passive barrier, the gut may play active roles in the transport, conversion, and storage of metabolites. In spite of their potential impact on energy homeostasis, such roles are largely uncharacterized.

\section{Absorption of Carbohydrates and Proteins}

Following the breakdown of complex carbohydrates and proteins by digestive enzymes, a diverse array of transporters internalizes simple sugars and amino acids into the enterocyte for further digestion and/or absorption (see 16, 114 for reviews). Many of the mammalian transporter families are present in Drosopbila, including the facilitative glucose transporters of the GLUT family (60), cationic amino acid transporters (38), ion-dependent and -independent amino acid transporters for neutral amino acids $(70,108,117,149)$, and dipeptide transporters (154). However, intestinal expression has only been reported for the amino acid transporters pathetic, minidiscs, and $N A T 1$ and the dipeptide transporter yin (opt1) $(70,117,154)$, and the roles of these transport systems in the intestine remain to be established. Although many of them may handle dietary nutrients, some may be involved in absorption of fermented and symbiotic products. A case in point is the broad neutral amino acid transporter NAT1, which is expressed in the larval posterior midgut and is able to transport both L- and D-isomers of several amino acids (117). D-isomers are particularly abundant in the cell walls of bacteria and can substitute essential L-amino acids in the Drosophila diet (68), suggesting that NAT1 may normally function to absorb substrates from bacteriaenriched fermented diets (16). Of note, AAT1, the closest relative of Drosophila NAT1 in Aedes aegypti, has limited capacity for transporting Disomers (16). This suggests that the absorption machinery is optimized to the specific diet.

\section{Absorption of Lipids}

Dietary triglyceride is broken down to yield monoglycerides and fatty acids, which can 
then be absorbed, along with dietary sterols, by intestinal cells. In the intestine, triglyceride is resynthesized and packaged together with cholesterol and fat body-derived carrier proteins to form lipoprotein particles, which are trafficked throughout the body (137). Our knowledge of intestinal lipid transport in Drosophila is still rudimentary, but 14 Drosophila homologs of the mammalian cluster of differentiation 36 (CD36)/scavenger receptor class B type 1 gene family have recently been identified (81). The intestinal expression of 12 of these 14 Drosophila CD36-like genes (81) points to their possible function in lipid uptake or metabolism, given that these proteins can mediate the transport of lipoproteins and fatty acids in mammals.

Unlike mammals, insects are unable to synthesize sterols from acetate and thus require a dietary source of sterol for the synthesis of the steroid-molting hormone ecdysone. Niemann-pick C1 (NPC1) proteins are 13transmembrane proteins possessing a sterolsensing domain that play a key role in intestinal absorption and intracellular trafficking of sterol in mammals (88). The Drosophila genome encodes eight NPC2 and two NPC1 homologs. Although NPC1a and NPC2a are required for intracellular sterol trafficking (87), NPC1b is expressed in a specific midgut compartment and is required for intestinal sterol absorption. An NPC1b mutation causes early larval lethality, possibly because of a defect in ecdysone synthesis that results from a sterol deficit $(129,189)$. Interestingly, NPC genes are targets of the transcription factor DHR96, the activity of which is enhanced upon cholesterol scarcity, providing a homeostatic link between dietary cholesterol and its transport machinery $(25,129)$.

\section{Absorption of Ions and Water}

In insects, specialized structures in or associated with the adult digestive tract play essential roles in maintaining the ionic concentration of the hemolymph: the Malpighian tubules, anal pads, and the hindgut. The maintenance of ion gradients is also essential to support secondary active transport. This is exemplified by the sodiumglucose linked transporter (SGLT), which uses the energy from a sodium gradient created by an ATP-ase pump to transport glucose across the apical membrane.

In Drosophila, the nature of intestinal ion gradients has been characterized by Naikkhwah \& O'Donnell (123), who used the scanning ionselective electrode technique in isolated guts of third instar larvae. This revealed that $\mathrm{K}^{+}$and $\mathrm{Na}^{+}$absorption occurs in specific portions of the midgut and hindgut and is subject to dietary regulation. Indeed, reduced cation absorption and increased secretion are observed in response to salt stress. The molecular machinery involved in shuttling ions and water molecules across the intestinal epithelium has only been partly characterized. Five genes encoding homologs of the cation-chloride SLC12 cotransporters are expressed in relevant tissues (gut, anal pads, and Malpighian tubules). However, single deletions of two of these genes (CG4357 and CG10413) did not result in any obvious phenotypes $(62,173)$. Similarly, knockdown of an abundant anion exchanger of the SLC4 family (CG8177) throughout the midgut had no effect on viability (54). The Drosophila genome also encodes six water aquaporins, five of which are enriched in regions R2 and R3 of the midgut (93), but their role in maintaining fluid balance remains to be established.

\section{Incorporation of Metals}

Intestinal metal absorption has been the focus of several in-depth studies that have revealed evolutionarily conserved mechanisms of uptake, storage, and export. Metals such as iron, zinc, and copper are essential micronutrients. However, their toxicity at high concentrations requires sophisticated mechanisms of uptake and storage. The middle midgut, notably the copper-cell region, is devoted to the absorption of these metals $(63,118)$. This region is stained by Prussian blue because of the presence of iron and becomes bright luminescent orange upon
Malpighian tubules: branching tubules extending from the alimentary canal at the level of the midguthindgut junction with excretory and osmoregulatory functions

Aquaporins: integral membrane proteins that form pores in the membranes of biological cells. Some are involved in water transport 
copper ingestion as a result of the fixation of copper by metallothionein $(58,111)$.

Copper is internalized by three intestinal Ctr1 family importers: Ctr1A, Ctr1B, and Ctr1C. Ctr1B is expressed at the brush border and is upregulated under low copper conditions (202). $C t r 1 B$ mutants die at the larval stage when copper is scarce, whereas heterozygotes are viable but show melanization defects, reflecting the requirement for copper as a cofactor for enzymes involved in pigmentation (202). Copper export from the intestine to the hemolymph is mediated by the P-type ATPase dATP7, which is localized at the basal membrane (26). Iron uptake is, in part, mediated by the divalent transporter ion transporter 1 (DMT1) homolog Malvolio (11). In addition to their role in iron storage, ferritins also mediate iron export from the midgut to the hemolymph $(107,181)$. Finally, zinc absorption is mediated by ZIP transporters, whereas zinc efflux from the cytoplasm to the hemolymph is mediated by $\mathrm{ZnT}$ transporters. The Drosophila genome encodes eight $Z i p$ genes and six $Z n T$ genes with different expression patterns along the gut (106, 197). Silencing of one of them, $\mathrm{ZnT1}$, a transporter expressed at the basal membrane, results in developmental arrest upon dietary zinc restriction, whereas its overexpression causes hypersensitivity to zinc (190).

Many of the genes involved in the absorption and storage of metals are subject to homeostatic regulation. The conserved metal transcription factor MTF-1 is an important mediator that, strikingly, appears to be able to regulate different target genes depending on whether a specific metal is scarce or too abundant $(160,166)$. For example, it promotes expression of the copper transporter Ctr1B when copper is scarce (200), but it activates the expression of four metallothionein proteins (cysteine-rich proteins able to sequester metals) in intestines exposed to high copper diets $(8$, $58,130)$.

In addition to transport, metal storage is another important target of homeostatic regulation. Indeed, larvae are able to accumulate copper to overcome a period of copper scarcity
(8). Finally, behavioral adaptations (e.g., avoidance of high copper food) may also contribute to maintaining metal homeostasis (8).

\section{INTESTINAL TRANSIT AND EXCRETION}

The differential availability of digestive enzymes and transporters provides one possible mechanism by which digestive and absorptive processes can be adjusted to nutritional demands. The nutritional state is also known to regulate processes such as the transit of food along the alimentary canal as well as food excretion. These modes of regulation, summarized below, may in turn affect the extent to which this food is utilized.

Pulse-chase experiments using food dyes have revealed that food can travel the entire length of the digestive tract in less than an hour (193), but this process is actively regulated by nutrient availability at the levels of intestinal capacity and excretion. Indeed, crop size is much larger in diet-restricted or sugar-fed flies than in fully fed flies $(57,193)$ (Figure 3a), and starvation has been shown to reduce the rate of defecation long before the gut is emptied (37). Further evidence for active regulation of intestinal transit and excretion is provided by the finding that, in spite of their increased food intake, female flies actively engaged in reproduction reduce their defecation rate and concentrate their intestinal contents and excreta (37). This response does not result from passive allocation of fluid/nutrients to egg production or from changes in renal function. Instead, it is mediated by a sex hormone that acts on a subset of hindgut-innervating neurons (37) (see below for details). Changes in intestinal fluid retention are likely to involve the distal part of the hindgut (the rectum and/or rectal glands), given its role in water reabsorption in other insects (49), and may help maximize absorption at a time of high nutritional demand. However, the precise link between fluid retention, absorption, and intestinal peristalsis is currently unknown. An important checkpoint in this regard may occur at the level of the crop, 
where differential peristalsis and engorgement can determine whether food is temporarily stored in this organ or released into the midgut for digestion and absorption (170).

Finally, it is noteworthy that, in addition to intestinal transit and defecation rate, the nature of excreta is also subject to complex homeostatic regulation. Indeed, the hindgut has been shown to differentially adjust the final $\mathrm{pH}$ of intestinal contents prior to excretion in response to both external (nutrient scarcity or imbalance) and internal (reproductive) challenges, presumably offsetting the excess acid produced by these metabolic stressors (37). In addition to modulating absorption, the aforementioned differences in intestinal transit and excretion might impact other aspects of intestinal homeostasis, such as stem cell renewal, immunity, and senescence. This hypothesis awaits further investigation.

\section{REGULATION OF INTESTINAL FUNCTIONS BY THE VISCERAL NERVOUS SYSTEM AND ENDOCRINE SIGNALS}

Coordination of gut functions, such as digestion, absorption, transit, and excretion, requires the existence of a system capable of sensing intestinal state and regulating intestinal functions. Recent data point to a central role for both enteric neurons and endocrine signals in these processes.

\section{Enteric Neurons}

The adult digestive tract receives innervation from three sources (Figure $3 \boldsymbol{c}, \boldsymbol{d}$ ): (a) the stomatogastric nervous system (SNS) $(39,78,168)$; (b) the corpus cardiacum, a neurosecretory structure that, in adult flies, is fused with one of the stomatogastric ganglia (the hypocerebral ganglion) (99); and (c) neurons located in the central nervous system (CNS), which extend their axons toward three sections of the digestive tract $(37,115,116,179)$.

Unlike the mammalian enteric nervous system, which populates the entire length of the gastrointestinal tract, the fly's digestive tract is only innervated in three distinct regions: the esophagus-crop-anterior midgut, the midguthindgut junction, and the posterior hindgut (37) (Figure 3c). Muscle valves are present in all three regions, consistent with the idea that peristaltic regulation is one of the main functions of these intestinal neurons. Although most neuronal fibers terminate on the visceral muscles, some reach the underlying epithelium (37). Epithelial innervation is particularly prominent in the esophagus, pyloric valve, and rectal ampulla (all of which are ectodermally derived epithelia). This is reminiscent of the organization of the mammalian submucosal plexus and, as such, is suggestive of neuronal regulation of epithelial properties, such as secretion and absorption (see below for one such example).

Not all innervation is efferent. Dendrites emanating from peripheral sensory neurons are apparent in the anterior- and posterior-most regions of the digestive tract (37), and they appear most abundant in the esophagus and anterior midgut (P. Cognigni \& I. MiguelAliaga, unpublished data). Very few neurons may contribute to this sensory innervation given that few peripheral cell bodies are found in close proximity to the digestive tract (P. Cognigni \& I. Miguel-Aliaga, unpublished data), and many of them are likely to be efferent cell bodies residing in the stomatogastric ganglia (Figure $3 d$ ).

Although there have been few neuroanatomical studies of the larval or adult digestive tract, they have nonetheless shown enteric innervation to be chemically and neuroanatomically diverse. Indeed, neuronal fibers positive for serotonin and several neuropeptides have been described in its anterior portion, including dromyosuppressin, adipokinetic hormone, and, possibly, allatostatin-C and FMRFamide (or an FMRFamide-like peptide, such as $\mathrm{SNPF})(24,99,110,128)$. Fibers positive for pigment-dispersing hormone, ion transport peptide, and proctolin have also been observed in both the larval and/or adult hindgut $(5,46$, $47,115,125)$. It is noteworthy that all three
Stomatogastric nervous system (SNS): discrete clusters (or ganglia) of neuronal cell bodies residing on and innervating the anterior portion of the digestive tract

Pyloric valve (or pylorus): constriction that separates the midgut and hindgut, and from which the Malpighian systems extend

Rectal ampulla (or rectal sac): enlargement of the posterior portion of the adult hindgut, consisting of a thin-walled epithelium and four rectal glands or pads

Submucosal plexus (or Meissner's plexus): the nerve branches and ganglia of the submucous coat of the mammalian intestine that innervate the epithelium and smooth muscles 
Pars intercerebralis: a neurosecretory center of the insect brain, located along the anterior midline innervated regions receive insulinergic innervation, whether emanating from the pars intercerebralis insulin-producing cells (the axons of which extend beyond the ring gland toward the anterior midgut and crop in adult flies) or the insulin-like peptide 7 (Ilp7)producing neurons of the abdominal ganglion (which innervate the midgut-hindgut junction and rectal ampulla) $(27,116)$. Intriguingly, the two populations of insulin-producing neurons appear to make direct synaptic contacts in the CNS (37), suggesting that they may function as an interconnected circuit to regulate the delivery of insulin to different portions of the digestive tract (see below for functional analyses). a

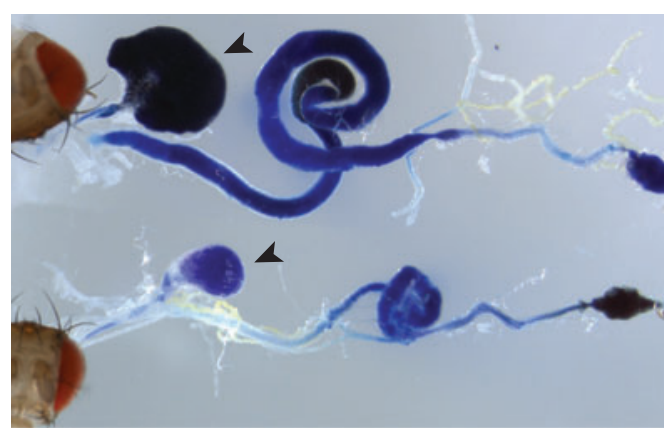

b

C

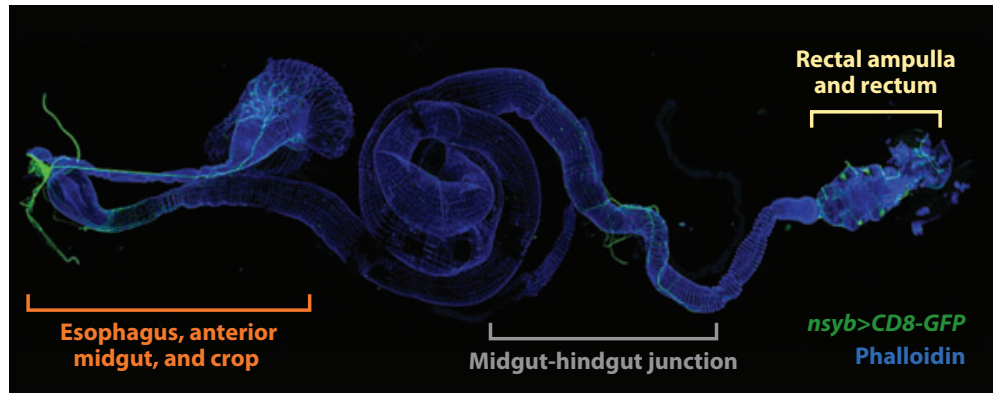

d

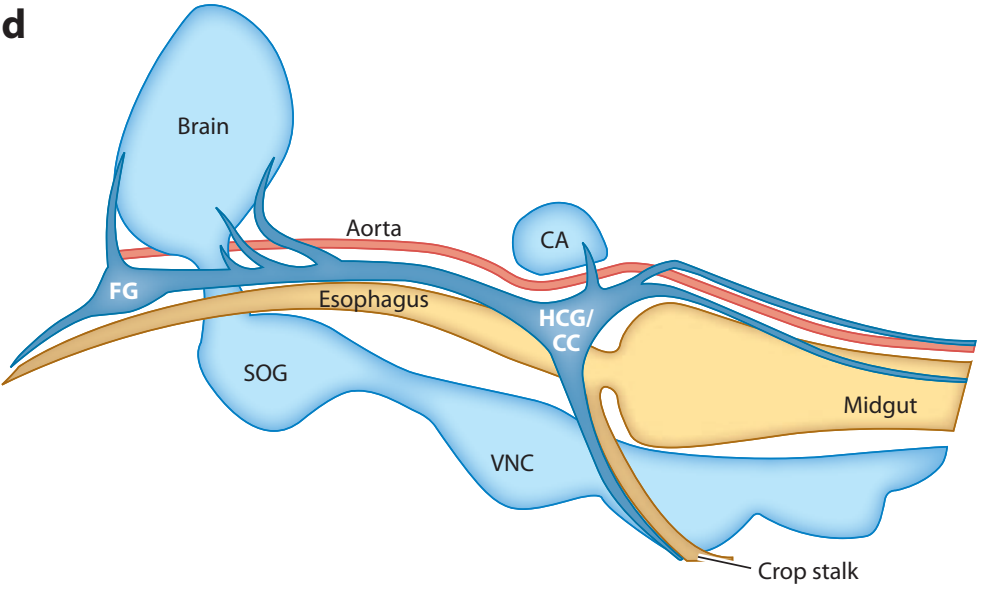




\section{Intestinal and Nonintestinal Roles of Enteric Neurons}

Historically, investigations of the neural control of gut physiology in arthropods have favored crustaceans or insects other than Drosophila because of their larger size. These studies have primarily focused on peristalsis, with a few exceptions. Although the generation and propagation of peristaltic waves has not been investigated in Drosophila, experiments in locusts have suggested the existence of central pattern generators in two stomatogastric ganglia: the frontal and hypocerebral ganglia (7, 144). However, once initiated, peristaltic waves must be able to propagate by myogenic transmission. This is suggested by the lack of innervation of some portions of the digestive tract, including, strikingly, the main digestive and absorptive portion of the midgut (37). Myogenic transmission of electrical activity in the absence of innervation has been demonstrated across the gastroduodenal junction of cats, dogs, and primates (14).

The few studies of peristaltic regulation in Drosophila have concerned the effects of neuropeptides, such as dromyosuppressin, allatostatin-C, and drosulfakinin, on ex vivo intestinal preparations $(92,138,142)$. These studies have ascribed distinct roles for these peptides in the modulation of crop contractions; dromyosuppressin stops crop contractions without recovery, whereas allatostatin-C reduces their frequency, but its effect partially reverses within a few minutes after applying the peptide. Drosulfakinin decreases adult, but not larval, contractions. Although the in vivo significance of these effects remains to be established, the neural control of peristalsis is likely to be physiologically relevant. Transit time appears to be regulated by nutrition and reproductive state in Drosophila (37). Similarly, circulating sugars control both peristalsis and the relative amount of food stored in the crop in Drosophila and other insects $(57,69,153,186)$. Hence, enteric neurons may act to control food passage between the crop and the midgut to match digestion and absorption to nutritional requirements.

Classical contraction assays have also recently been combined with modern genetic and imaging techniques to demonstrate a nonintestinal role in the regulation of renal physiology for a set of hindgut-innervating neurons, the pigment dispersing factor (PDF)expressing neurons, located in the abdominal ganglion of the CNS (179). It was found that PDF produced by these neurons promotes the peristalsis of the muscles of the ureters, the proximal part of the Malpighian tubules.

Figure 3

Intestinal transit, excretion, and innervation in Drosophila melanogaster. (a) Effect of different diets on crop size (black arrowheads). An engorged crop is often apparent following ingestion of a sugar-rich meal (top digestive tract). (b) Drosophila excreta. Supplementation of the fly's diet with a $\mathrm{pH}$ indicator dye reveals deposits of different $\mathrm{pH}$. Several features of excreta, including $\mathrm{pH}$, are regulated by both diet and internal state (37). (c) Dissected adult digestive tract of a fly expressing the membrane-tagged reporter CD 8 -GFP from the pan-neuronal driver n-synaptobrevin-Gal4. The gut is counterstained with actin to highlight the muscles [phalloidin (blue)]. Anterior is to the left. Innervation emanating from the central nervous system (CNS), stomatogastric nervous system (SNS), and corpus cardiacum is apparent anteriorly in the esophagus, anterior midgut, and crop (orange bracket). More posteriorly, two nerves predominantly formed by axons emanating from CNS neurons bifurcate when they reach the gut to innervate the posterior midgut-anterior hindgut junction and its pyloric valve (gray bracket) and the posterior-most portion of the digestive tract, comprising the rectal ampulla and rectum (yellow bracket). Note that this neuronal reporter is also weakly expressed in enteroendocrine cells. (d) Graphic summarizing the connectivity between SNS ganglia-corpus cardiacum (dark blue), CNS neurons (light blue), and adjacent organs, including the anterior portion of the digestive tract (tan). Anterior is to the left. Abbreviations: CA, corpus allatum; CC, corpus cardiacum; FG, frontal ganglion; HCG, hypocerebral ganglion; SOG, subesophageal ganglion; VNC, ventral nerve cord. 
Hence, some enteric neurons may use the digestive tract as a docking site to exert their functions on other internal organs at some distance.

More integrative in vivo approaches are revealing neuronal regulation of features other than muscle contractions. Indeed, a new method based on the semiautomated analysis of defecation behavior (Figure $3 \boldsymbol{b}$ ), providing quantitative readouts for food intake, fluidion balance, and intestinal transit, has uncovered the first enteric neurons to regulate fluid balance in invertebrates. The HGN1 neurons comprise a group of two to five CNS neurons located in the posterior segments of the abdominal ganglion, the axons of which reach the hindgut and project through the visceral muscles to reach the underlying epithelium (37). Neuronal silencing experiments have revealed that HGN1 neurons, consistent with their epithelial innervation, are required for the postmating changes in intestinal fluid retention described above. Interestingly, GRASP [GFP (green fluorescent protein) reconstitution across synaptic partners] analysis (71) has suggested direct synaptic contact between the axonal terminals of the sex peptide-receiving sensory neurons in the reproductive tract (known to relay mating status to affect postmating behavior) with HGN1 dendrites in the abdominal ganglion (P. Cognigni \& I. MiguelAliaga, unpublished data). Hence, this finding provides the first example of a simple circuit that couples the reproductive and digestive systems, bypassing the brain to effect visceral changes in response to the reproductive state.

\section{Endocrine Regulation of Intestinal Functions by Systemic Signals and Enteroendocrine Cell Hormones}

In addition to being subject to direct neural control, the Drosophila gut may also be regulated by extrinsic hormonal signals (emanating from endocrine glands or neuroendocrine organs) and by its own peptides, which are produced by the EECs. The former kind of regulation is suggested by the intestinal expression of receptors for neurotransmitters or peptides not produced by gut-innervating neurons or EECs (188). One such example is the leucokinin receptor, which is expressed by both the Malpighian tubules and the digestive tract, and binds to leucokinin: a diuretic peptide secreted systemically from the CNS-derived nerves that terminate at the abdominal wall $(3,37,132,143)$. Downregulation of either this peptide or its receptor leads to abnormal excreta and extreme fluid retention that, on occasion, ruptures the abdominal wall, with both visceral muscles and the stellate cells of the tubule contributing to this phenotype (37; P. Cognigni \& I. Miguel-Aliaga, unpublished results). The finding of such a severe phenotype for a CNS peptide on visceral physiology highlights the importance of this systemic mode of regulation.

EECs are abundant and diverse in the midgut (see Table $\mathbf{1}$ for a list of EEC peptides) $(134,145,188)$. Given that this is the portion of the digestive tract least profusely innervated (37), midgut EECs may carry out some neurallike functions in regulating intestinal physiology and/or conveying the intestinal/nutritional state to other internal organs. In this regard, it is perhaps not surprising that the developmental program of EECs shares similarities with that of neurons, probably reflecting a common phylogenetic origin of these cell types $(77,175)$. Consistent with this idea, all the peptides produced by EECs are also present in the CNS, hence their brain-gut peptide denomination.

Currently, very little is known about the functions and modes of action of the EECs and their peptides. In mammals, secreted EEC peptides can enter the bloodstream to affect tissues at a considerable distance, ranging from other portions of the digestive tract to the brain centers that regulate appetite (91). It is unclear whether any of the Drosophila EEC peptides are released into the circulation. EEC peptides can also act more locally, and such a local role was recently suggested by the finding that a subset of DH31-producing EECs regulates midgut peristalsis in Drosophila larvae, pointing to the visceral muscle as one site of EEC peptide action (98). Although tantalizing, these findings also illustrate the difficulties of ascribing functions 
Table 1 Peptide hormones present in the adult midgut ${ }^{a}$

\begin{tabular}{|c|c|c|c|}
\hline Gene & LC-MS & Microarray & In situ/immunohistochemistry \\
\hline$A k b$ (CG1171) & - & $?$ & axons (ant) (99) \\
\hline Ast (CG13633) & + & + & EECs (post) \\
\hline Ast-C (CG14919) & + & + & EECs (ant, mid, post) \\
\hline burs (CG13419) & - & + & $\mathrm{N} / \mathrm{I}$ \\
\hline CCHa1 (CG14358) & + & + & $\mathrm{N} / \mathrm{I}$ \\
\hline CCHa2 (CG14375) & + & + & $\mathrm{N} / \mathrm{I}$ \\
\hline Dh31 (CG13094) & + & + & EECs (post) \\
\hline Ilp3 (CG14167) & - & + & muscle subset $(19,188)$ \\
\hline itp (CG13586) & - & + & axons (post) (47) \\
\hline Mip (CG6456) & + & + & EECs (post)? \\
\hline$n p f(\mathrm{CG} 10342)$ & - & + & EECs (ant, mid) (18) \\
\hline$P d f($ CG6496) & + & - & axons (post) $(80,125,179)$ \\
\hline Ptth (CG13687) & - & + & $\mathrm{N} / \mathrm{I}$ \\
\hline$s N P F(C G 13968)$ & + & $?$ & axons (ant) \\
\hline$T k(\mathrm{CG} 14734)$ & + & + & EECs (ant, mid, post) \\
\hline
\end{tabular}

a Only peptide hormones detected by mass spectrometry (145), microarray analyses (34), or immunohistochemistry (188) are listed (unless otherwise indicated). Note that the source of these peptides may be the EECs or axons innervating the anterioror posterior-most portions of the midgut. Discrepancies between mass spectrometry and RNA-protein data result from the fact that large peptides are not readily detectable by mass spectrometry. Abbreviations: ant, anterior; EECs, enteroendocrine cells; LC-MS, liquid chromatography-mass spectrometry; mid, middle; N/I, not investigated; post, posterior.

to EEC peptides; given the similarities between neurons and EECs, it remains difficult to silence a gene in EECs without affecting its expression in neurons.

\section{REACHING OUT: INTESTINAL SENSORS, APPETITE REGULATION, AND ENERGY HOMEOSTASIS}

The findings described above indicate that the fly's digestive tract is equipped with the anatomical substrates for interorgan signaling: sensory neurons and/or EECs. Such signaling might be used exclusively to relay information back to the CNS with the overall goal of monitoring, maintaining, and temporally organizing intestinal functions. However, intestinal signaling could be involved in more integrative functions by, for example, coupling intestinal state with behavioral and metabolic adaptations to nutrient availability. Flies are known to adapt their food intake and preference to both exter- nal nutrient availability and their internal state $(29,44,57,64,150)$. Given that the nutritional requirements of Drosophila are fairly complex [including proteins, carbohydrates, cholesterol, choline/lecithin, salts, and a subset of vitamins (158)] and that the digestive tract is the first internal organ to come in contact with nutrients, this organ is particularly well placed to sense and relay nutritional signals to modulate behavior and metabolism. The following two sections summarize its possible role in these processes.

\section{Intestinal Nutrient Sensing: Molecular Sensors}

Although the sensory innervation of the digestive tract is sparse, it may be significant. In the context of nutrient sensing, the recent report of four peripheral neurons on the proventriculus that express the gustatory receptor Gr43a is intriguing (119). These neurons extend dendritic processes in the foregut lumen, and their axons innervate either the midgut muscles or the 
CNS at the level of the subesophageal ganglion; hence, they may both relay nutritional information back to the CNS and act locally. Moreover, the ability of the gut to sense nutrients may not be confined to its neurons: At least 12 gustatory receptors have been recently reported to be expressed in subsets of EECs (140), raising the possibility that, as in mammals, EECs modulate their secretion of hormones in response to nutrient quality/quantity. The functional relevance of the taste receptors in intestinal sensory neurons and EECs requires further genetic analyses that can distinguish between their roles in the intestine versus those in more traditional external taste structures, such as the proboscis.

The existence of neuronal stretch receptors on the crop and anterior midgut that monitor the volume of ingested food is well supported by both neurophysiological and anatomical data in several other insects (reviewed in 165). These experiments have established their functional importance locally, in regulating intestinal physiology, and remotely, in the control of food intake. However, the presence and molecular nature of these receptors in Drosophila remain to be elucidated.

\section{Relaying Nutritional Information: Intestinal Regulation of Appetite and Nutrient Storage}

The digestive tract may make use of the nutritional information acquired by the sensors listed above to control its own functions. Furthermore, tantalizing findings suggest that the gut may also be able to relay nutritional information to the brain or other internal organs. Indeed, effects on food intake in response to nutrient scarcity have been observed when crop- or hindgut-innervating, insulin-producing neurons are inactivated (37). It is conceivable that these neurons use the gut merely as a docking point to release insulin systemically and affect other tissues. However, more local targets of action are suggested by the findings that different insulin-producing neurons have different effects on food intake when inactivated and that they innervate different portions of the diges- tive tract (37). Similar effects on appetite have also been reported upon mutation of genes expressed in the anterior portion of the digestive tract. Indeed, mutants lacking the putative juvenile hormone-binding protein termed Takeout, normally expressed in the proventriculus and crop and induced in additional portions of the digestive tract by starvation, also fail to adapt their food intake according to food availability $(112,159)$. Although the expression of Takeout in tissues other than the gut (such as taste neurons) may partly account for this phenotype, the role of intestinal Takeout deserves further investigation.

Further studies are needed to determine whether the behavioral changes caused by the above genetic manipulations result from a gutto-brain signal or from more indirect effects on metabolism, which might be sensed elsewhere. Experiments in other insect species, however, provide some evidence for direct gut-to-brain communication emanating from the crop and involving peripheral stretch receptors, which would relay information about crop engorgement back to the CNS to limit food intake in the blowfly $(9,45,170)$. The link between crop physiology, diet, and sensory activity is much more tenuous in Drosophila, but, intriguingly, mutations in the dropdead gene, which lead to neurodegeneration (20), are associated with increased crop size and reduced transfer of ingested food from the crop to the midgut (141).

Whether relayed by neuronal or hormonal means, the possible neural targets of intestinal signaling in the CNS are also unknown. Intriguingly, the brain-gut peptide NPF (the fly ortholog of mammalian NPY) has been shown to promote feeding and make starved larvae more willing to take in noxious food $(195,196)$. More recently, NPF has been shown to bind to its receptor in central dopaminergic neurons to regulate appetitive memory in adult flies (95). It will be of interest to determine whether the dopaminergic neurons are a target of systemic NPF emanating from the gut. Together, the above studies point to the existence of complex interactions between the gut and other tissues 
but highlight the need to identify the signaling mechanisms involved.

\section{CONCLUSIONS}

Organs such as the fly wing or brain have proven to be instrumental in uncovering fundamental principles of development. The functional complexity, plasticity, and genetic amenability of the Drosophila gut are allowing the study of not only developmental but also physiological questions in this fascinating organ. However, our knowledge of its functional intricacies is still rudimentary. The shift in focus in Drosophila research from "how to make a fly" to "how a fly works" is timely in this regard, and we anticipate interactions between the genetically minded Drosophila community and the more physiology-oriented entomologists to be fruitful in the coming years. Many features of digestion and absorption appear to be conserved between flies and mammals, which is a likely legacy of the ancestral origin of the alimentary canal. Investigation of these processes in this simpler model system may contribute to the identification of metabolically relevant molecules, which could become drug targets for the treatment of metabolic disorders.

On a more speculative note, it is intriguing that the genes and signaling pathways that the adult gut uses to maintain its homeostasis have all been involved in developmental processes. Given that the gut was one of the first organs to arise during metazoan evolution, it is conceivable that the ancestral function of many signaling modules traditionally regarded as developmental (such as transcription factors or morphogens) was to maintain the structural compartmentalization of the gut or even to orchestrate digestion, and that these signaling modules were later co-opted into playing a role during embryonic development. Thus, revisiting the function of developmental pathways in the context of gut immunity or stem cell maintenance may cast a new light on such pathways. Similarly, the already apparent similarities between EECs and neurons suggest that the study of EECs may shed light on conserved principles of neuronal development. Hence, we anticipate fields as diverse as metabolism, immunity, and neurobiology to benefit from future genetic analyses of intestinal homeostasis.

\section{SUMMARY POINTS}

1. The compartmentalized and dynamic natures of the adult gut make it an excellent model organ to both revisit basic developmental processes and investigate homeostatic tissue interactions or mechanisms of tissue maintenance.

2. The gut is a complex barrier where the internal and the external environments interact through metabolic, repair, and immune pathways.

3. The Drosophila genome encodes a vast repertoire of digestive enzymes and transporters. Sophisticated regulation of digestive and absorptive processes may be crucial to the success of this species.

4. As with the mammalian gastrointestinal tract, the fly's digestive tract is equipped with a diverse neuronal and hormonal repertoire. Sensory neurons and EEC hormones may mediate interorgan signaling to effect metabolic and behavioral adaptations.

\section{FUTURE ISSUES}

1. It will be important to investigate the establishment and maintenance of gut compartmentalization during the Drosophila life cycle and upon intestinal damage. 
2. Characterizing the mechanisms underlying gut senescence and determining their contribution to aging will be vital.

3. Another step will be to determine how digestive enzymes and transporters are regulated to coordinate and modulate digestion.

4. Characterizing the neuronal and hormonal repertoire of the adult gut and establishing their homeostatic roles, both in the intestine and systemically, will be key to our understanding.

\section{DISCLOSURE STATEMENT}

The authors are not aware of any affiliations, memberships, funding, or financial holdings that might be perceived as affecting the objectivity of this review.

\section{ACKNOWLEDGMENTS}

The authors apologize for their inability to cite many other substantial contributions, notably on stem cell regulation, because of space limitations. We thank Wen Bin (Alfred) Chng, Paola Cognigni, Dani Osman, Véronique Dijkstra-Bulliard, and Maroun Bou Sleiman for their assistance with the preparation of this manuscript and figures, and we are grateful to Ronald Dubreuil, Marie Meister, Steve Perlman, William Schaffner, and Christian Wegener for providing insightful comments.

\section{LITERATURE CITED}

1. Abraham I, Doane WW. 1978. Genetic regulation of tissue-specific expression of amylase structural genes in Drosophila melanogaster. Proc. Natl. Acad. Sci. USA 75:4446-50

2. Acosta Muniz C, Jaillard D, Lemaitre B, Boccard F. 2007. Erwinia carotovora Evf antagonizes the elimination of bacteria in the gut of Drosophila larvae. Cell Microbiol. 9:106-19

3. Al-Anzi B, Armand E, Nagamei P, Olszewski M, Sapin V, et al. 2010. The leucokinin pathway and its neurons regulate meal size in Drosophila. Curr. Biol. 20:969-78

4. Amcheslavsky A, JiangJ, Ip YT. 2009. Tissue damage-induced intestinal stem cell division in Drosophila. Cell Stem Cell 4:49-61

5. Anderson MS, Halpern ME, Keshishian H. 1988. Identification of the neuropeptide transmitter proctolin in Drosophila larvae: characterization of muscle fiber-specific neuromuscular endings. F. Neurosci. $8: 242-55$

6. Anton-Erxleben F, Miquel J, Philpott DE. 1983. Fine-structural changes in the midgut of old Drosopbila melanogaster. Mech. Ageing Dev. 23:265-76

7. Ayali A, Zilberstein Y, Cohen N. 2002. The locust frontal ganglion: a central pattern generator network controlling foregut rhythmic motor patterns. F. Exp. Biol. 205:2825-32

8. Balamurugan K, Egli D, Hua H, Rajaram R, Seisenbacher G, et al. 2007. Copper homeostasis in Drosophila by complex interplay of import, storage and behavioral avoidance. EMBO 7. 26:1035-44

9. Belzer WR. 1978. Recurrent nerve inhibition of protein feeding in the blowfly Phormia regina. Physiol. Entomol. 3:259-63

10. Benkel BF, Hickey DA. 1986. Glucose repression of amylase gene expression in Drosophila melanogaster. Genetics 114:137-44

11. Bettedi L, Aslam MF, Szular J, Mandilaras K, Missirlis F. 2011. Iron depletion in the intestines of Malvolio mutant flies does not occur in the absence of a multicopper oxidase. F. Exp. Biol. 214:971-78 
12. Biteau B, Hochmuth CE, Jasper H. 2008. JNK activity in somatic stem cells causes loss of tissue homeostasis in the aging Drosophila gut. Cell Stem Cell 3:442-55

13. Biteau B, Karpac J, Supoyo S, Degennaro M, Lehmann R, Jasper H. 2010. Lifespan extension by preserving proliferative homeostasis in Drosophila. PLoS Genet. 6:e1001159

14. Bortoff A, Davis RS. 1968. Myogenic transmission of antral slow waves across the gastroduodenal junction in situ. Am. 7. Physiol. 215:889-97

15. Bosco-Drayon V, Poidevin M, Boneca IG, Narbonne-Reveau K, Royet J, Charroux B. 2012. Peptidoglycan sensing by the receptor PGRP-LE in the Drosophila gut induces immune responses to infectious bacteria and tolerance to microbiota. Cell Host Microbe 16:153-65

16. Boudko DY. 2012. Molecular basis of essential amino acid transport from studies of insect nutrient amino acid transporters of the SLC6 family (NAT-SLC6). F. Insect Physiol. 58:433-49

17. Broderick NA, Lemaitre B. 2012. Gut-associated microbes of Drosophila melanogaster. Gut Microbes 3:307-21

18. Brown MR, Crim JW, Arata RC, Cai HN, Chun C, Shen P. 1999. Identification of a Drosophila brain-gut peptide related to the neuropeptide Y family. Peptides 20:1035-42

19. Buch S, Melcher C, Bauer M, Katzenberger J, Pankratz MJ. 2008. Opposing effects of dietary protein and sugar regulate a transcriptional target of Drosophila insulin-like peptide signaling. Cell Metab. 7:32132

20. Buchanan RL, Benzer S. 1993. Defective glia in the Drosophila brain degeneration mutant drop-dead. Neuron 10:839-50

21. Buchon N, Broderick NA, Chakrabarti S, Lemaitre B. 2009. Invasive and indigenous microbiota impact intestinal stem cell activity through multiple pathways in Drosophila. Genes Dev. 23:2333-44

21a. Buchon N, Broderick NA, Lemaitre B. 2013. Gut homeostasis in a microbial world: insights from Drosophila melanogaster. Nat. Rev. Microbiol. 16:615-26

22. Buchon N, Broderick NA, Poidevin M, Pradervand S, Lemaitre B. 2009. Drosophila intestinal response to bacterial infection: activation of host defense and stem cell proliferation. Cell Host Microbe 5:200-11

23. Buchon N, Osman D, David FPA, Yu Fang H, Boquete JP, Deplancke B, Lemaitre B. 2013. Morphological and molecular characterization of adult midgut compartmentalization in Drosophila. Cell Rep. $3: 1725-38$

24. Budnik V, Wu CF, White K. 1989. Altered branching of serotonin-containing neurons in Drosophila mutants unable to synthesize serotonin and dopamine. F. Neurosci. 9:2866-77

25. Bujold M, Gopalakrishnan A, Nally E, King-Jones K. 2010. Nuclear receptor DHR96 acts as a sentinel for low cholesterol concentrations in Drosophila melanogaster. Mol. Cell. Biol. 30:793-805

26. Burke R, Commons E, Camakaris J. 2008. Expression and localisation of the essential copper transporter DmATP7 in Drosophila neuronal and intestinal tissues. Int. 7. Biochem. Cell Biol. 40:1850-60

27. Cao C, Brown MR. 2001. Localization of an insulin-like peptide in brains of two flies. Cell Tissue Res. 304:317-21

28. Carlson JR, Hogness DS. 1985. The Jonah genes: a new multigene family in Drosophila melanogaster. Dev. Biol. 108:341-54

29. Carvalho GB, Kapahi P, Benzer S. 2005. Compensatory ingestion upon dietary restriction in Drosophila melanogaster. Nat. Methods 2:813-15

30. Chandler JA, Lang JM, Bhatnagar S, Eisen JA, Kopp A. 2011. Bacterial communities of diverse Drosophila species: ecological context of a host-microbe model system. PLoS Genet. 7:e1002272

31. Charroux B, Royet J. 2009. Elimination of plasmatocytes by targeted apoptosis reveals their role in multiple aspects of the Drosophila immune response. Proc. Natl. Acad. Sci. USA 106:9797-802

32. Chatterjee M, Ip YT. 2009. Pathogenic stimulation of intestinal stem cell response in Drosophila. 7 . Cell. Physiol. 220:664-71

33. Chen J, Xie C, Tian L, Hong L, Wu X, Han J. 2010. Participation of the p38 pathway in Drosophila host defense against pathogenic bacteria and fungi. Proc. Natl. Acad. Sci. USA 107:20774-79

34. Chintapalli VR, Wang J, Dow JAT. 2007. Using FlyAtlas to identify better Drosophila melanogaster models of human disease. Nat. Genet. 39:715-20

35. Choi Y-J, Hwang M-S, Park J-S, Bae S-K, Kim YS, Yoo M-A. 2008. Age-related upregulation of Drosophila caudal gene via NF-KB in the adult posterior midgut. Biochim. Biophys. Acta 1780:1093-100 
36. Clissold FJ, Tedder BJ, Conigrave AD, Simpson SJ. 2010. The gastrointestinal tract as a nutrientbalancing organ. Proc. R. Soc. B 277:1751-59

37. Cognigni P, Bailey AP, Miguel-Aliaga I. 2011. Enteric neurons and systemic signals couple nutritional and reproductive status with intestinal homeostasis. Cell Metab. 13:92-104

38. Colombani J, Raisin S, Pantalacci S, Radimerski T, Montagne J, Leopold P. 2003. A nutrient sensor mechanism controls Drosophila growth. Cell 114:739-49

39. Copenhaver PF. 2007. How to innervate a simple gut: familiar themes and unique aspects in the formation of the insect enteric nervous system. Dev. Dyn. 236:1841-64

40. Cordero JB, Stefanatos RK, Scopelliti A, Vidal M, Sansom OJ. 2012. Inducible progenitor-derived Wingless regulates adult midgut regeneration in Drosophila. EMBO F. 31:3901-17

41. Da Lage JL, Maczkowiak F, Cariou ML. 2000. Molecular characterization and evolution of the amylase multigene family of Drosophila ananassae. 7. Mol. Evol. 51:391-403

42. Davis MM, Engstrom Y. 2012. Immune response in the barrier epithelia: lessons from the fruit fly Drosophila melanogaster. 7. Innate Immun. 4:273-83

43. Demerec M, ed. 1950. Biology of Drosophila. New York: John Wiley \& Sons

44. Dethier VG. 1976. The Hungry Fly: A Physiological Study of Behaviour Associated with Feeding. Boston: Harvard Univ. Press

45. Dethier VG, Gelperin A. 1967. Hyperphagia in the blowfly. 7. Exp. Biol. 47:191-200

46. Dircksen H. 2009. Insect ion transport peptides are derived from alternatively spliced genes and differentially expressed in the central and peripheral nervous system. F. Exp. Biol. 212:401-12

47. Dircksen H, Tesfai LK, Albus C, Nassel DR. 2008. Ion transport peptide splice forms in central and peripheral neurons throughout postembryogenesis of Drosophila melanogaster. 7. Comp. Neurol. 509:2341

48. Douglas AE. 2011. Lessons from studying insect symbioses. Cell Host Microbe 10:359-67

49. Douglas AE. 2013. The alimentary canal. In The Insects: Structure and Function, ed. RF Chapman, SJ Simpson, AE Douglas, pp. 46-80. Cambridge, UK: Cambridge Univ. Press

50. Dow JA. 2003. The Drosophila phenotype gap: and how to close it. Brief Funct. Genomic Proteomic 2:121-27

51. Dow JA. 1999. The multifunctional Drosophila melanogaster V-ATPase is encoded by a multigene family. 7. Bioenerg. Biomembr. 31:75-83

52. Dow JA, Evans PD, Wigglesworth VB. 1987. Insect midgut function. Adv. Insect Physiol. 19:187-328

53. Dubreuil RR. 2004. Copper cells and stomach acid secretion in the Drosophila midgut. Int. F. Biochem. Cell Biol. 36:745-52

54. Dubreuil RR, Das A, Base C, Mazock GH. 2010. The Drosophila anion exchanger (DAE) lacks a detectable interaction with the spectrin cytoskeleton. F. Negat. Results Biomed. 9:5

55. Dubreuil RR, Frankel J, Wang P, Howrylak J, Kappil M, Grushko TA. 1998. Mutations of alpha spectrin and labial block cuprophilic cell differentiation and acid secretion in the middle midgut of Drosophila larvae. Dev. Biol. 194:1-11

56. Dubreuil RR, Grushko T, Baumann O. 2001. Differential effects of a labial mutation on the development, structure, and function of stomach acid-secreting cells in Drosophila melanogaster larvae and adults. Cell Tissue Res. 306:167-78

57. Edgecomb RS, Harth CE, Schneiderman AM. 1994. Regulation of feeding behavior in adult Drosophila melanogaster varies with feeding regime and nutritional state. F. Exp. Biol. 197:215-35

58. Egli D, Yepiskoposyan H, Selvaraj A, Balamurugan K, Rajaram R, et al. 2006. A family knockout of all four Drosophila metallothioneins reveals a central role in copper homeostasis and detoxification. Mol. Cell. Biol. 26:2286-96

59. Erkosar B, Storelli G, Defaye A, Leulier F. 2013. Host-intestinal microbiota mutualism: "learning on the fly." Cell Host Microbe 13:8-14

60. Escher SA, Rasmuson-Lestander A. 1999. The Drosophila glucose transporter gene: cDNA sequence, phylogenetic comparisons, analysis of functional sites and secondary structures. Hereditas 130:95-103

61. Ferrandon D. 2012. The complementary facets of epithelial host defenses in the genetic model organism Drosophila melanogaster: from resistance to resilience. Curr. Opin. Immunol. 25:59-70 
62. Filippov V, Aimanova K, Gill SS. 2003. Expression of an Aedes aegypti cation-chloride cotransporter and its Drosophila homologues. Insect Mol. Biol. 12:319-31

63. Filshie BK, Poulson DF, Waterhouse DF. 1971. Ultrastructure of the copper-accumulating region of the Drosophila larval midgut. Tissue Cell 3:77-102

64. Fujita M, Tanimura T. 2011. Drosopbila evaluates and learns the nutritional value of sugars. Curr. Biol. 21:751-55

65. Gartner LP. 1973. Ultrastructural examination of ageing and radiation-induced life-span shortening in adult Drosophila melanogaster. Int. 7. Radiat. Biol. Relat. Stud. Phys. Chem. Med. 23:23-39

66. Gartner LP. 1976. Fine-structure of adult Drosophila midgut musculature. F. Submicroscop. Cytol. Pathol. 8:131-36

67. Gartner LP. 1985. The fine structural morphology of the midgut of adult Drosophila: a morphometric analysis. Tissue Cell 17:883-88

68. Geer BW. 1966. Utilization of D-amino acids for growth by Drosophila melanogaster larvae. F. Nutr. 90:31-39

69. Gelperin A. 1966. Investigations of a foregut receptor essential to taste threshold regulation in the blowfly. F. Insect Physiol. 12:829-41

70. Goberdhan DC, Meredith D, Boyd CA, Wilson C. 2005. PAT-related amino acid transporters regulate growth via a novel mechanism that does not require bulk transport of amino acids. Development $132: 2365-75$

71. Gordon MD, Scott K. 2009. Motor control in a Drosophila taste circuit. Neuron 61:373-84

72. Guo Z, Driver I, Ohlstein B. 2013. Injury-induced BMP signaling negatively regulates Drosophila midgut homeostasis. 7. Cell Biol. 201:945-61

73. Ha E-M, Lee K-A, Park SH, Kim S-H, Nam H-J, et al. 2009. Regulation of DUOX by the galphaqphospholipase $\mathrm{C} \beta-\mathrm{Ca}^{2+}$ pathway in Drosophila gut immunity. Dev. Cell 16:386-97

74. Ha E-M, Oh C-T, Bae Y-S, Lee WJ. 2005. A direct role for dual oxidase in Drosophila gut immunity. Science 310:847-50

75. Ha E-M, Oh C-T, Ryu JH, Bae Y-S, Kang S-W, et al. 2005. An antioxidant system required for host protection against gut infection in Drosophila. Dev. Cell 8:125-32

76. Haj-Ahmad Y, Hickey DA. 1982. A molecular explanation of frequency-dependent selection in Drosophila. Nature 299:350-52

77. Hartenstein V, Takashima S, Adams KL. 2010. Conserved genetic pathways controlling the development of the diffuse endocrine system in vertebrates and Drosophila. Gen. Comp. Endocrinol. 166:462-69

78. Hartenstein V, Tepass U, Gruszynski-Defeo E. 1994. Embryonic development of the stomatogastric nervous system in Drosophila. 7. Comp. Neurol. 350:367-81

79. Hegedus D, Erlandson M, Gillott C, Toprak U. 2009. New insights into peritrophic matrix synthesis, architecture, and function. Annu. Rev. Entomol. 54:285-302

80. Helfrichforster C, Homberg U. 1993. Pigment-dispersing hormone-immunoreactive neurons in the nervous system of wild-type Drosophila melanogaster and of several mutants with altered circadian rhythmicity. F. Comp. Neurol. 337:177-90

81. Herboso L, Talamillo A, Perez C, Barrio R. 2011. Expression of the scavenger receptor class B type I (SR-BI) family in Drosophila melanogaster. Int. F. Dev. Biol. 55:603-11

82. Hickey DA, Benkel BF, Abukashawa S, Haus S. 1988. DNA rearrangement causes multiple changes in gene expression at the amylase locus in Drosophila melanogaster. Biochem. Genet. 26:757-68

83. Hoppler S, Bienz M. 1994. Specification of a single cell type by a Drosophila homeotic gene. Cell 76:689-702

84. Horne I, Haritos VS. 2008. Multiple tandem gene duplications in a neutral lipase gene cluster in Drosophila. Gene 411:27-37

85. Horne I, Haritos VS, Oakeshott JG. 2009. Comparative and functional genomics of lipases in holometabolous insects. Insect Biochem. Mol. Biol. 39:547-67

86. Horner MA, Pardee K, Liu S, King-Jones K, Lajoie G, et al. 2009. The Drosophila DHR96 nuclear receptor binds cholesterol and regulates cholesterol homeostasis. Genes Dev. 23:2711-16 
87. Huang X, Warren JT, Buchanan J, Gilbert LI, Scott MP. 2007. Drosophila Niemann-Pick type C-2 genes control sterol homeostasis and steroid biosynthesis: a model of human neurodegenerative disease. Development 134:3733-42

88. Jia L, Betters JL, Yu L. 2011. Niemann-pick C1-like 1 (NPC1L1) protein in intestinal and hepatic cholesterol transport. Annu. Rev. Physiol. 73:239-59

89. Jiang H, Edgar BA. 2011. Intestinal stem cells in the adult Drosophila midgut. Exp. Cell Res. 317:2780-88

90. Jiang H, Patel PH, Kohlmaier A, Grenley MO, McEwen DG, Edgar BA. 2009. Cytokine/Jak/Stat signaling mediates regeneration and homeostasis in the Drosophila midgut. Cell 137:1343-55

91. Johnson LR, ed. 2006. Physiology of the Gastrointestinal Tract. San Diego, CA: Elsevier

92. Kaminski S, Orlowski E, Berry K, Nichols R. 2002. The effects of three Drosophila melanogaster myotropins on the frequency of foregut contractions differ. F. Neurogenet. 16:125-34

93. Kaufmann N, Mathai JC, Hill WG, Dow JA, Zeidel ML, Brodsky JL. 2005. Developmental expression and biophysical characterization of a Drosophila melanogaster aquaporin. Am. 7. Physiol. Cell Physiol. 289:C397-407

94. King D. 1988. Cellular organization and peritrophic membrane formation in the cardia (proventriculus) of Drosophila melanogaster. F. Morphol. 196:253-82

95. Krashes MJ, DasGupta S, Vreede A, White B, Armstrong JD, Waddell S. 2009. A neural circuit mechanism integrating motivational state with memory expression in Drosophila. Cell 139:416-27

96. Kuraishi T, Binggeli O, Opota O, Buchon N, Lemaitre B. 2011. Genetic evidence for a protective role of the peritrophic matrix against intestinal bacterial infection in Drosophila melanogaster. Proc. Natl. Acad. Sci. USA 108:15966-71

97. Kylsten P, Kimbrell DA, Daffre S, Samakovlis C, Hultmark D. 1992. The lysozyme locus in Drosophila melanogaster: Different genes are expressed in midgut and salivary glands. Mol. Gen. Genet. 232:335-43

98. LaJeunesse DR, Johnson B, Presnell JS, Catignas KK, Zapotoczny G. 2010. Peristalsis in the junction region of the Drosopbila larval midgut is modulated by DH31 expressing enteroendocrine cells. BMC Physiol. 10:14

99. Lee G, Park JH. 2004. Hemolymph sugar homeostasis and starvation-induced hyperactivity affected by genetic manipulations of the adipokinetic hormone-encoding gene in Drosophila melanogaster. Genetics 167:311-23

100. Lee KA, Kim SH, Kim EK, Ha EM, You H, et al. 2013. Bacterial-derived uracil as a modulator of mucosal immunity and gut-microbe homeostasis in Drosophila. Cell 153:797-811

101. Lehane MJ. 1997. Peritrophic matrix structure and function. Annu. Rev. Entomol. 42:525-50

102. Lehane MJ, Billingsley PF. 1996. Biology of the Insect Midgut. Heidelberg, Ger.: Springer

103. Lehane MJ, Blakemore D, Williams S, Moffatt MR. 1995. Regulation of digestive enzyme levels in insects. Comp. Biochem. Physiol. B 110:285-89

104. Lhocine N, Ribeiro PS, Buchon N, Wepf A, Wilson R, et al. 2008. PIMS modulates immune tolerance by negatively regulating Drosophila innate immune signaling. Cell Host Microbe 4:147-58

105. Li Z, Zhang Y, Han L, Shi L, Lin X. 2013. Trachea-derived DPP controls adult midgut homeostasis in Drosophila. Dev. Cell 24:133-43

106. Lye JC, Richards CD, Dechen K, Paterson D, de Jonge MD, et al. 2012. Systematic functional characterization of putative zinc transport genes and identification of zinc toxicosis phenotypes in Drosopbila melanogaster. 7. Exp. Biol. 215:3254-65

107. Mandilaras K, Pathmanathan T, Missirlis F. 2013. Iron absorption in Drosophila melanogaster. Nutrients 5:1622-47

107a. Marianes A, Spradling AC. 2013. Physiological and stem cell compartmentalization within the Drosophila midgut. eLife 2:e00886

108. Martin JF, Hersperger E, Simcox A, Shearn A. 2000. minidiscs encodes a putative amino acid transporter subunit required non-autonomously for imaginal cell proliferation. Mech. Dev. 92:155-67

109. Mathur D, Bost A, Driver I, Ohlstein B. 2010. A transient niche regulates the specification of Drosophila intestinal stem cells. Science 327:210

110. McCormick J, Nichols R. 1993. Spatial and temporal expression identify dromyosuppressin as a braingut peptide in Drosophila melanogaster. F. Comp. Neurol. 338:278-88 
111. McNulty M, Puljung M, Jefford G, Dubreuil RR. 2001. Evidence that a copper-metallothionein complex is responsible for fluorescence in acid-secreting cells of the Drosophila stomach. Cell Tissue Res. 304:383-89

112. Meunier N, Belgacem YH, Martin JR. 2007. Regulation of feeding behaviour and locomotor activity by takeout in Drosophila. 7. Exp. Biol. 210:1424-34

113. Micchelli CA, Perrimon N. 2006. Evidence that stem cells reside in the adult Drosophila midgut epithelium. Nature 439:475-79

114. Miguel-Aliaga I. 2012. Nerveless and gutsy: intestinal nutrient sensing from invertebrates to humans. Semin. Cell Dev. Biol. 23:614-20

115. Miguel-Aliaga I, Thor S. 2004. Segment-specific prevention of pioneer neuron apoptosis by cellautonomous, postmitotic Hox gene activity. Development 131:6093-105

116. Miguel-Aliaga I, Thor S, Gould AP. 2008. Postmitotic specification of Drosophila insulinergic neurons from pioneer neurons. PLoS Biol. 6:e58

117. Miller MM, Popova LB, Meleshkevitch EA, Tran PV, Boudko DY. 2008. The invertebrate B(0) system transporter, D. melanogaster NAT1, has unique D-amino acid affinity and mediates gut and brain functions. Insect Biochem. Mol. Biol. 38:923-31

118. Missirlis F, Kosmidis S, Brody T, Mavrakis M, Holmberg S, et al. 2007. Homeostatic mechanisms for iron storage revealed by genetic manipulations and live imaging of Drosophila ferritin. Genetics 177:89100

119. Miyamoto T, Slone J, Song X, Amrein H. 2012. A fructose receptor functions as a nutrient sensor in the Drosophila brain. Cell 151:1113-25

120. Murakami R, Shigenaga A, Kawano E, Matsumoto A, Yamaoka I, Tanimura T. 1994. Novel tissue units of regional differentiation in the gut epithelium of Drosophila, as revealed by P-element-mediated detection of enhancer. Rouxs Arch. Dev. Biol. 203:243-49

121. Murakami R, Shiotsuki Y. 2001. Ultrastructure of the hindgut of Drosophila larvae, with special reference to the domains identified by specific gene expression patterns. F. Morphol. 248:144-50

122. Musselman LP, Fink JL, Narzinski K, Ramachandran PV, Hathiramani SS, et al. 2011. A high-sugar diet produces obesity and insulin resistance in wild-type Drosophila. Dis. Models Mech. 4:842-49

123. Naikkhwah W, O'Donnell MJ. 2012. Phenotypic plasticity in response to dietary salt stress: $\mathrm{Na}^{+}$and $\mathrm{K}^{+}$transport by the gut of Drosophila melanogaster larvae. F. Exp. Biol. 215:461-70

124. Nakagoshi H. 2005. Functional specification in the Drosophila endoderm. Dev. Growth Differ. 47:383-92

125. Nassel DR, Shiga S, Mohrherr CJ, Rao KR. 1993. Pigment-dispersing hormone-like peptide in the nervous system of the flies Phormia and Drosophila: immunocytochemistry and partial characterization. 7. Comp. Neurol. 331:183-98

126. Nation JL. 2002. Insect Physiology and Biochemistry. Boca Raton, FL: CRC Press. 485 pp.

127. Neyen C, Poidevin M, Roussel A, Lemaitre B. 2012. Tissue- and ligand-specific sensing of gramnegative infection in Drosophila by PGRP-LC isoforms and PGRP-LE. F. Immunol. 189:1886-97

128. Nichols R, Bendena WG, Tobe SS. 2002. Myotropic peptides in Drosophila melanogaster and the genes that encode them. F. Neurogenet. 16:1-28

129. Niwa R, Niwa YS. 2011. The fruit fly Drosophila melanogaster as a model system to study cholesterol metabolism and homeostasis. Cholesterol 2011:176802

130. Norgate M, Southon A, Zou S, Zhan M, Sun Y, et al. 2007. Copper homeostasis gene discovery in Drosophila melanogaster. Biometals 20:683-97

131. O'Brien LE, Soliman SS, Li X, Bilder D. 2011. Altered modes of stem cell division drive adaptive intestinal growth. Cell 147:603-14

132. O’Donnell MJ, Dow JA, Huesmann GR, Tublitz NJ, Maddrell SH. 1996. Separate control of anion and cation transport in Malpighian tubules of Drosophila melanogaster. F. Exp. Biol. 199:1163-75

133. Ohlstein B, Spradling A. 2007. Multipotent Drosophila intestinal stem cells specify daughter cell fates by differential notch signaling. Science 315:988-92

134. Ohlstein B, Spradling AC. 2006. The adult Drosophila posterior midgut is maintained by pluripotent stem cells. Nature 439:470-74

135. Okumura T, Tajiri R, Kojima T, Saigo K, Murakami R. 2007. GATAe-dependent and -independent expressions of genes in the differentiated endodermal midgut of Drosophila. Gene Expr. Patterns 7:178-86 
136. Osman D, Buchon N, Chakrabarti S, Huang YT, Su WC, et al. 2012. Autocrine and paracrine unpaired signaling regulate intestinal stem cell maintenance and division. 7. Cell Sci. 125(Pt. 4):5944-49

137. Palm W, Sampaio JL, Brankatschk M, Carvalho M, Mahmoud A, et al. 2012. Lipoproteins in Drosophila melanogaster: assembly, function, and influence on tissue lipid composition. PLoS Genet. 8:e1002828

138. Palmer GC, Tran T, Duttlinger A, Nichols R. 2007. The drosulfakinin 0 (DSK 0) peptide encoded in the conserved Dsk gene affects adult Drosophila melanogaster crop contractions. F. Insect Physiol. 53:1125-33

139. Paredes JC, Welchman DP, Poidevin M, Lemaitre B. 2011. Negative regulation by amidase PGRPs shapes the Drosophila antibacterial response and protects the fly from innocuous infection. Immunity 35:770-79

140. Park JH, Kwon JY. 2011. Heterogeneous expression of Drosopbila gustatory receptors in enteroendocrine cells. PLoS ONE 6:e29022

141. Peller CR, Bacon EM, Bucheger JA, Blumenthal EM. 2009. Defective gut function in drop-dead mutant Drosophila. F. Insect Physiol. 55:834-39

142. Price MD, Merte J, Nichols R, Koladich PM, Tobe SS, Bendena WG. 2002. Drosophila melanogaster flatline encodes a myotropin orthologue to Manduca sexta allatostatin. Peptides 23:787-94

143. Radford JC, Davies SA, Dow JA. 2002. Systematic G-protein-coupled receptor analysis in Drosophila melanogaster identifies a leucokinin receptor with novel roles. 7. Biol. Chem. 277:38810-17

144. Rand D, Ayali A. 2010. Neuroanatomy and neurophysiology of the locust hypocerebral ganglion. 7. Insect Physiol. 56:884-92

145. Reiher W, Shirras C, Kahnt J, Baumeister S, Isaac RE, Wegener C. 2011. Peptidomics and peptide hormone processing in the Drosophila midgut. F. Proteome Res. 10:1881-92

146. Ren C, Webster P, Finkel SE, Tower J. 2007. Increased internal and external bacterial load during Drosophila aging without life-span trade-off. Cell Metab. 6:144-52

147. Rera M, Bahadorani S, Cho J, Koehler CL, Ulgherait M, et al. 2011. Modulation of longevity and tissue homeostasis by the Drosophila PGC-1 homolog. Cell Metab. 14:623-34

148. Rera M, Clark RI, Walker DW. 2012. Intestinal barrier dysfunction links metabolic and inflammatory markers of aging to death in Drosophila. Proc. Natl. Acad. Sci. USA 109:21528-33

149. Reynolds B, Roversi P, Laynes R, Kazi S, Boyd CA, Goberdhan DC. 2009. Drosophila expresses a CD98 transporter with an evolutionarily conserved structure and amino acid-transport properties. Biochem. 7. $420: 363-72$

150. Ribeiro C, Dickson BJ. 2010. Sex peptide receptor and neuronal TORS6K signaling modulate nutrient balancing in Drosophila. Curr. Biol. 20:1000-5

151. Ridley EV, Wong AC, Westmiller S, Douglas AE. 2012. Impact of the resident microbiota on the nutritional phenotype of Drosophila melanogaster. PLoS ONE 7:e36765

152. Rizki TM. 1956. The secretory activity of the proventriculus of Drosophila melanogaster. 7. Exp. Zool. 131:203-21

153. Roces F, Blatt J. 1999. Haemolymph sugars and the control of the proventriculus in the honey bee Apis mellifera. 7. Insect Physiol. 45:221-29

154. Roman G, Meller V, Wu KH, Davis RL. 1998. The opt1 gene of Drosophila melanogaster encodes a proton-dependent dipeptide transporter. Am. F. Physiol. 275:C857-69

155. Ross J, Jiang H, Kanost MR, Wang Y. 2003. Serine proteases and their homologs in the Drosopbila melanogaster genome: an initial analysis of sequence conservation and phylogenetic relationships. Gene 304:117-31

156. Ryu JH, Kim SH, Lee HY, Bai JY, Nam YD, et al. 2008. Innate immune homeostasis by the homeobox gene caudal and commensal-gut mutualism in Drosopbila. Science 319:777-82

157. Ryu JH, Nam K-B, Oh C-T, Nam H-J, Kim S-H, et al. 2004. The homeobox gene Caudal regulates constitutive local expression of antimicrobial peptide genes in Drosophila epithelia. Mol. Cell. Biol. 24:172-85

158. Sang JH. 1956. The quantitative nutritional requirements of Drosophila melanogaster. F. Exp. Biol. 33:4572

159. Sarov-Blat L, So WV, Liu L, Rosbash M. 2000. The Drosophila takeout gene is a novel molecular link between circadian rhythms and feeding behavior. Cell 101:647-56 
160. Selvaraj A, Balamurugan K, Yepiskoposyan H, Zhou H, Egli D, et al. 2005. Metal-responsive transcription factor (MTF-1) handles both extremes, copper load and copper starvation, by activating different genes. Genes Dev. 19:891-6

161. Shanbhag S, Tripathi S. 2005. Electrogenic H+ transport and $\mathrm{pH}$ gradients generated by a V-H+ -ATPase in the isolated perfused larval Drosopbila midgut. 7. Membr. Biol. 206:61-72

162. Shanbhag S, Tripathi S. 2009. Epithelial ultrastructure and cellular mechanisms of acid and base transport in the Drosophila midgut. F. Exp. Biol. 212:1731-44

163. Shin SC, Kim SH, You H, Kim B, Kim AC, et al. 2011. Drosophila microbiome modulates host developmental and metabolic homeostasis via insulin signaling. Science 334:670-4

164. Sieber MH, Thummel CS. 2012. Coordination of triacylglycerol and cholesterol homeostasis by DHR96 and the Drosophila LipA homolog magro. Cell Metab. 15:122-7

165. Simpson SJ, Douglas AE 2013. Nutrition. In The Insects: Structure and Function, ed. RF Chapman, SJ Simpson, AE Douglas, pp. 81-106 Cambridge, UK: Cambridge Univ. Press

166. Sims HI, Chirn GW, Marr MT 2nd. 2012. Single nucleotide in the MTF-1 binding site can determine metal-specific transcription activation. Proc. Natl. Acad. Sci. USA 109:16516-21

167. Singh SR, Zeng X, Zheng Z, Hou SX. 2011. The adult Drosophila gastric and stomach organs are maintained by a multipotent stem cell pool at the foregut/midgut junction in the cardia (proventriculus). Cell Cycle 10:1109-20

168. Spiess R, Schoofs A, Heinzel HG. 2008. Anatomy of the stomatogastric nervous system associated with the foregut in Drosophila melanogaster and Calliphora vicina third instar larvae. F. Morphol. 269:272-82

169. Stainier DY. 2005. No organ left behind: tales of gut development and evolution. Science 307:1902-4

170. Stoffolano JG Jr, Haselton AT. 2013. The adult dipteran crop: a unique and overlooked organ. Annu. Rev. Entomol. 58:205-25

171. Storelli G, Defaye A, Erkosar B, Hols P, Royet J, Leulier F. 2011. Lactobacillus plantarum promotes Drosophila systemic growth by modulating hormonal signals through TOR-dependent nutrient sensing. Cell Metab. 14:403-14

172. Strand M, Micchelli CA. 2011. Quiescent gastric stem cells maintain the adult Drosophila stomach. Proc. Natl. Acad. Sci. USA 108:17696-701

173. Sun Q, Tian E, Turner RJ, Ten Hagen KG. 2010. Developmental and functional studies of the SLC12 gene family members from Drosophila melanogaster. Am. 7. Physiol. Cell Physiol. 298:C26-37

174. Syed ZA, Hard T, Uv A, van Dijk-Hard IF. 2008. A potential role for Drosophila mucins in development and physiology. PLoS ONE 3:e3041

175. Takashima S, Adams KL, Ortiz PA, Ying CT, Moridzadeh R, et al. 2011. Development of the Drosophila entero-endocrine lineage and its specification by the Notch signaling pathway. Dev. Biol. 353:161-72

176. Takashima S, Hartenstein V. 2012. Genetic control of intestinal stem cell specification and development: a comparative view. Stem Cell Rev. 8:597-608

177. Takashima S, Mkrtchyan M, Younossi-Hartenstein A, Merriam JR, Hartenstein V. 2008. The behaviour of Drosophila adult hindgut stem cells is controlled by Wnt and Hh signalling. Nature 454:651-55

178. Takashima S, Younossi-Hartenstein A, Ortiz PA, Hartenstein V. 2011. A novel tissue in an established model system: the Drosophila pupal midgut. Dev. Genes Evol. 221:69-81

179. Talsma AD, Christov CP, Terriente-Felix A, Linneweber GA, Perea D, et al. 2012. Remote control of renal physiology by the intestinal neuropeptide pigment-dispersing factor in Drosophila. Proc. Natl. Acad. Sci. USA 109:12177-82

180. Tamaki FK, Padilha MH, Pimentel AC, Ribeiro AF, Terra WR. 2012. Properties and secretory mechanism of Musca domestica digestive chymotrypsin and its relation with Drosophila melanogaster homologs. Insect Biochem. Mol. Biol. 42:482-90

181. Tang X, Zhou B. 2013. Ferritin is the key to dietary iron absorption and tissue iron detoxification in Drosophila melanogaster. FASEB 7. 27:288-98

182. Terra WR. 1990. Evolution of digestive systems of insects. Annu. Rev. Entomol. 35:181-200

183. Terra WR. 2001. The origin and functions of the insect peritrophic membrane and peritrophic gel. Arch. Insect Biochem. Physiol. 47:47-61 
184. Terra WR, Ferreira AC, de Bianchi AG. 1979. Distribution of digestive enzymes among the endoand ectoperitrophic spaces and midgut cells of Rhynchosciara and its physiological significance. 7. Insect Physiol. 25:487-94

185. Thompson DB, Treat-Clemons LG, Doane WW. 1992. Tissue-specific and dietary control of alphaamylase gene expression in the adult midgut of Drosophila melanogaster. 7. Exp. Zool. 262:122-34

186. Treherne JE. 1957. Glucose absorption in the cockroach. 7. Exp. Biol. 34:478-85

187. Tzou P, Ohresser S, Ferrandon D, Capovilla M, Reichhart JM, et al. 2000. Tissue-specific inducible expression of antimicrobial peptide genes in Drosophila surface epithelia. Immunity 13:737-48

188. Veenstra JA, Agricola HJ, Sellami A. 2008. Regulatory peptides in fruit fly midgut. Cell Tissue Res. 334:499-516

189. Voght SP, Fluegel ML, Andrews LA, Pallanck LJ. 2007. Drosophila NPC1b promotes an early step in sterol absorption from the midgut epithelium. Cell Metab. 5:195-205

190. Wang X, Wu Y, Zhou B. 2009. Dietary zinc absorption is mediated by ZnT1 in Drosophila melanogaster. FASEB 7. 23:2650-61

191. Wong AC, Chaston JM, Douglas AE. 2013. The inconstant gut microbiota of Drosophila species revealed by $16 \mathrm{~S}$ rRNA gene analysis. ISME 7. 7:1922-32

192. Wong CN, Ng P, Douglas AE. 2011. Low-diversity bacterial community in the gut of the fruitfly Drosophila melanogaster. Environ. Microbiol. 13:1889-900

193. Wong R, Piper MD, Blanc E, Partridge L. 2008. Pitfalls of measuring feeding rate in the fruit fly Drosophila melanogaster. Nat. Methods 5:214-15; author reply 5

194. Woodring J, Diersch S, Lwalaba D, Hoffmann KH, Meyering-Vos M. 2009. Control of the release of digestive enzymes in the caeca of the cricket Gryllus bimaculatus. Physiol. Entomol. 34:144-51

195. Wu Q, Wen T, Lee G, Park JH, Cai HN, Shen P. 2003. Developmental control of foraging and social behavior by the Drosophila neuropeptide Y-like system. Neuron 39:147-61

196. Wu Q, Zhao Z, Shen P. 2005. Regulation of aversion to noxious food by Drosophila neuropeptide Yand insulin-like systems. Nat. Neurosci. 8:1350-55

197. Yepiskoposyan H, Egli D, Fergestad T, Selvaraj A, Treiber C, et al. 2006. Transcriptome response to heavy metal stress in Drosopbila reveals a new zinc transporter that confers resistance to zinc. Nucleic Acids Res. 34:4866-77

198. Zaidman-Remy A, Herve M, Poidevin M, Pili-Floury S, Kim MS, et al. 2006. The Drosophila amidase PGRP-LB modulates the immune response to bacterial infection. Immunity 24:463-73

199. Zaidman-Remy A, Regan JC, Brandao AS, Jacinto A. 2012. The Drosophila larva as a tool to study gut-associated macrophages: PI3K regulates a discrete hemocyte population at the proventriculus. Dev. Comp. Immunol. 36:638-47

200. Zhang B, Egli D, Georgiev O, Schaffner W. 2001. The Drosopbila homolog of mammalian zinc finger factor MTF-1 activates transcription in response to heavy metals. Mol. Cell. Biol. 21:4505-14

201. Zhang Z, Inomata N, Yamazaki T, Kishino H. 2003. Evolutionary history and mode of the amylase multigene family in Drosophila. F. Mol. Evol. 57:702-9

202. Zhou H, Cadigan KM, Thiele DJ. 2003. A copper-regulated transporter required for copper acquisition, pigmentation, and specific stages of development in Drosophila melanogaster. F. Biol. Chem. 278:48210-18

203. Zinke I, Schutz CS, Katzenberger JD, Bauer M, Pankratz MJ. 2002. Nutrient control of gene expression in Drosophila: microarray analysis of starvation and sugar-dependent response. EMBO F. 21:6162-73 


\section{Contents}

Causes of Genome Instability

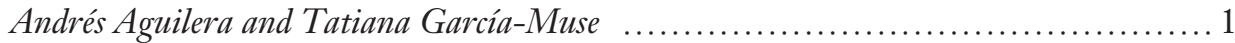

Radiation Effects on Human Heredity Nori Nakamura, Akibiko Suyama, Asao Noda, and Yosbiaki Kodama

Dissecting Social Cell Biology and Tumors Using Drosophila Genetics Fosé Carlos Pastor-Pareja and Tian Xu

Estimation and Partition of Heritability in Human Populations Using Whole-Genome Analysis Methods Anna A.E. Vinkbuyzen, Naomi R. Wray, Fian Yang, Micbael E. Goddard, and Peter M. Visscher

Detecting Natural Selection in Genomic Data Foseph 7. Vitti, Sharon R. Grossman, and Pardis C. Sabeti ...

Adaptive Translation as a Mechanism of Stress Response and Adaptation

Tao Pan

Organizing Principles of Mammalian Nonsense-Mediated mRNA Decay Maximilian Wei-Lin Popp and Lynne E. Maquat

Control of Nuclear Activities by Substrate-Selective and Protein-Group SUMOylation Stefan fentsch and Ivan Psakbye

Genomic Imprinting: Insights From Plants Mary Gebring

Regulation of Bacterial Metabolism by Small RNAs

Using Diverse Mechanisms

Maksym Bobrovskyy and Carin K. Vanderpool

Bacteria and the Aging and Longevity of Caenorbabditis elegans

Dennis H. Kim

The Genotypic View of Social Interactions in Microbial Communities

Sara Mitri and Kevin Richard Foster

SIR Proteins and the Assembly of Silent Chromatin in Budding Yeast

Stephanie Kueng, Mariano Oppikofer, and Susan M. Gasser ...
Annual Review of Genetics

Volume 47, 2013 (1) 
New Gene Evolution: Little Did We Know

Manyuan Long, Nicholas W. VanKuren, Sidi Chen, Maria D. Vibranovski

RNA Editing in Plants and Its Evolution

Mizuki Takenaka, Anja Zebrmann, Daniil Verbitskiy, Barbara Härtel, and Axel Brennicke....

Expanding Horizons: Ciliary Proteins Reach Beyond Cilia

Shiaulou Yuan and Zhaoxia Sun

The Digestive Tract of Drosophila melanogaster

Bruno Lemaitre and Irene Miguel-Aliaga

RNase III: Genetics and Function; Structure and Mechanism

Donald L. Court, Fianhua Gan, Yu-He Liang, Gary X. Shaw, Foseph E. Tropea, Nina Costantino, David S. Waugh, and Xinbua Fi

Modernizing the Nonhomologous End-Joining Repertoire:

Alternative and Classical NHEJ Share the Stage

Ludovic Deriano and David B. Roth

Enterococcal Sex Pheromones: Signaling, Social Behavior, and Evolution

Gary M. Dunny

Control of Transcriptional Elongation

Hojoong Kwak and Fobn T. Lis...

The Genomic and Cellular Foundations of Animal Origins

Daniel 7. Richter and Nicole King

Genetic Techniques for the Archaea

Foel A. Farkas, Fonathan W. Picking, and Thomas 7. Santangelo

Initation of Meiotic Recombination: How and Where? Conservation and Specificities Among Eukaryotes Bernard de Massy

Biology and Genetics of Prions Causing Neurodegeneration

Stanley B. Prusiner

Bacterial $\mathrm{Mg}^{2+}$ Homeostasis, Transport, and Virulence

Eduardo A. Groisman, Kerry Hollands, Michelle A. Kriner, Eun-7in Lee, Sun-Yang Park, and Mauricio H. Pontes

\section{Errata}

An online log of corrections to Annual Review of Genetics articles may be found at http://genet.annualreviews.org/errata.shtml 